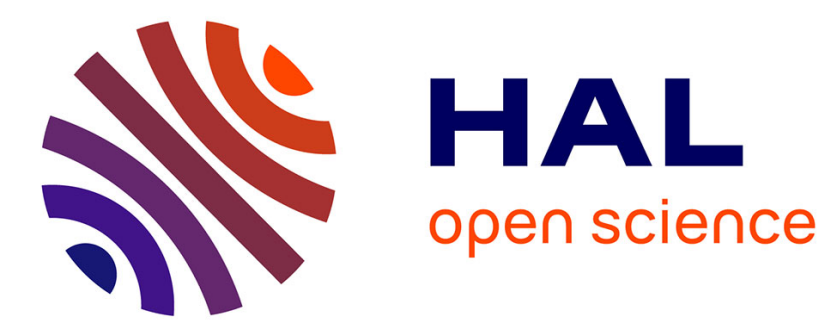

\title{
Strength and fatigue strength of a similar Ti-6Al-2Sn-4Zr-2Mo-0.1Si linear friction welded joint
}

Juan Manuel Garcia, Thilo F. Morgeneyer

\section{To cite this version:}

Juan Manuel Garcia, Thilo F. Morgeneyer. Strength and fatigue strength of a similar Ti-6Al-2Sn-4Zr2Mo-0.1Si linear friction welded joint. Fatigue and Fracture of Engineering Materials and Structures, 2019, 42 (5), pp.1100-1117. 10.1111/ffe.12973 . hal-02091184

\section{HAL Id: hal-02091184 \\ https://hal.science/hal-02091184}

Submitted on 20 Aug 2019

HAL is a multi-disciplinary open access archive for the deposit and dissemination of scientific research documents, whether they are published or not. The documents may come from teaching and research institutions in France or abroad, or from public or private research centers.
L'archive ouverte pluridisciplinaire HAL, est destinée au dépôt et à la diffusion de documents scientifiques de niveau recherche, publiés ou non, émanant des établissements d'enseignement et de recherche français ou étrangers, des laboratoires publics ou privés. 


\title{
Strength and fatigue strength of a similar $\mathrm{Ti}-6 \mathrm{Al}-2 \mathrm{Sn}-4 \mathrm{Zr}-2 \mathrm{Mo}-0.1 \mathrm{Si}$ linear friction welded joint
}

\author{
GARCIA J.M., MORGENEYER T.F. \\ MINES ParisTech, PSL - Research University, \\ Centre des Matériaux CNRS UMR 7633, BP 8791003 Evry, France
}

March 4, 2019

https://doi.org/10.1111/ffe.12973

Published in: Fatigue Fract Eng Mater Struct. 2019;1-18 (Wiley)

\author{
Correspondence \\ Juan Manuel García, MINES ParisTech, \\ PSL Research University, Centre des \\ Matériaux CNRS UMR 7633, BP 8791003 \\ Evry, France. \\ Email: jmgarcia.engineering@gmail.com \\ Funding information \\ Agence Nationale de la Recherche
}

\begin{abstract}
Strengths for monotonic and cyclic loadings of similar overmatching Ti6242 Linear Friction Welds (LFW) were studied and compared to the parent material (PM) behaviour. Non destructive synchrotron observations revealed the presence of pores in the weld interface. The Weld Centre Zone (WCZ) showed a higher strength leading to lower macroscopic ductility of the cross-weld samples. Local strain and normalized strain rate have been assessed by stereo Digital Image Correlation (DIC) and revealed an early plastic activity at yielding in the vicinity of the WCZ attributed to residual stresses. For the target life, the fatigue strength was slightly reduced but compromised by a strong scatter. Indeed, an internal fish-eye fatigue crack initiation was found on an unexpected dendritic defect that was very different from the PM microstructure and the known martensitic $\alpha^{\prime}$ in the WCZ. The dendritic defect was linked to surface contamination prior to welding and led to melting.
\end{abstract}

\section{Keywords}

Titanium alloy, Linear friction welding, Mechanical properties.

\section{Nomenclature:}

$\alpha$ (h.c.p.), hexagonal closed packed titanium crystal lattice; $\beta$ (b.c.c.), body centred cubic titanium crystal lattice; $F$, friction axis; $P$, pressure axis; $T$, thickness axis; $E$, Young's modulus; $Y$, yield strength; UTS, Ultimate Tensile Strength; $\varepsilon_{\text {macro }}$, macroscopic engineering strain; $\varepsilon_{\mathrm{PP}}$, local strain following the $P$ axis; $\dot{\varepsilon}_{\mathrm{PP}}$, local strain rate following the $P$ axis; $\sigma_{\varepsilon_{\mathrm{PP}}}$, standard deviation on the local strain following the $P$ axis during rigid body displacement; $\sigma_{\max }$, maximum fatigue stress; $R$, fatigue stress ratio; $N_{f}$, fatigue life; $\Delta K$, stress intensity factor; $a$, crack size; $d a / d N$ crack growth per cycle. 


\section{Introduction}

Titanium alloys are widely used in the aerospace industry [1]. An increasing demand of titanium and composite materials has recently been observed [2] due to the progressive growth of air traffic [3] and their high compatibility of working together, such as galvanic and thermal expansion coefficients compatibility and corrosion protection [4]. Titanium's excellent corrosion resistance, mechanical resistance and low density give them increasing importance. Ti6242 highlights a very good creep resistance and it enables working in high temperature environments [5].

A need to improve the buy-to-fly ratio is raising and it could be satisfied, e.g. by the use of novel joining techniques [1]. Linear Friction Welding (LFW) is solid-state joining process which was first patented by [6] and it works as follows: A cantilever workpiece, also known as stationary workpiece, is in contact with a second piece named the oscillating workpiece which follows a linear oscillatory motion. After a fraction of a second of friction, a forging pressure is applied to achieve a target axial shortening. High levels of plastic deformation and localized heat are generated around the weld interface following four distinct phases. Microstructural changes, unknown mechanical properties and considerable levels of residual stresses are found in four distinct welding zones [7] : the weld centre zone (WCZ), the thermo-mechanically affected zone (TMAZ), the heat affected zone (HAZ) and the parent material (PM). This process is very quick, reduces bulk milling operations, enables the conception of dissimilar welds and, in some cases, enhanced weld mechanical properties.

LFW joints may be subjected to strong mechanical and cyclic loadings $[8,9,10,11]$. Understanding their mechanical properties in monotonic and cyclic loadings is fundamental for its industrial application. Several authors studied the tensile properties of similar LFW joints using as parent material comparable alloys to Ti6242, such as TA6V and IMI-834 $[8,10,11,12,13,14,15,16,17,18,19]$. Some similar and dissimilar joints failed far from the WCZ [10,12, 14, 15, 17, 18]. For instance, [20] observed that the formation of a fine microstructure in the WCZ of a similar IMI-834 LFW joint led to a weld overmatch. In a similar manner, [13] documented the weld overmatch of a Ti-6Al-4V LFW joint.

During tensile tests, the macroscopic strains are typically measured using standard extensometers. This measurement represents a limited relevance while testing cross-weld specimens due to the heterogeneous material microstructure, associated strain heterogeneity and presence of residual stresses. Advancements on experimental mechanics such as Digital Image Correlation (DIC) shed new light on the strain monitoring. The assessment of the strain fields on cross-weld specimens has already been exploited by several authors [15, 21, 22, 23]. For the last 20 years a large number of authors have used spatio temporal graphs to highlight the presence of strain bands due to instabilities of Portevin's Le Chatelier effect and the Lüders bands. Yet, very little attention has been given to the chronological strain evolution and strain rate in the weld zones during tensile test.

Friction Stir Welding (FSW) is one of the most broadcast solid state joining processes and it is known for having different kind of defects. The most common defect is called joint line remnant, "lazy S" or "zig-zag curve" ([24]) and it consists on a line of oxides that zigzags along the thickness of the weld. Another typical defect is called "kissing bond" or "root flaw" and consists of the final part of the JLR remaining open, due to an insufficient penetration of the tool pin [25]. The two sheets to be welded by FSW must be closer than a given threshold distance, when this distance is not respected, another kind of defect called the "GAP" takes place leading to the presence of cavities [25]. Some surface defects related to excessive heat input have also been observed such as flash formation, surface galling and nugget collapse.

Concerning the documented defects in $L F W$, literature is less abundant. Some of the documented defects are porosity, oxides and the formation of an abnormal microstructure [26, 27]. [26] found that either oxides or porosity could appear in the WCZ as a function of the chosen LFW parameters.

Some authors studied the effects of FSW welds defects on the tensile properties [28]. For instance, [29], [30] and [31] documented the effect of defects on the tensile strength of FSW joints. The weld properties of sound welds and welds containing defects were similar even if surface defects such as kissing bond acted as crack initiation site during tensile tests. Despite the existence of pores and oxides, some resistance to a monotonic loading can be obtained. [26] observed the presence of oxides and pores in the WCZ of similar Ti-6Al-4V LFW joints and yet failure always occurred in the TMAZ or the PM. [12] and [27] reported the presence of abnormal 
microstructures in the WCZ of similar Ti alloys LFW joints which resulted into failure in the elastic domain with a quasi brittle fracture.

The consequences of FSW defects in terms of fatigue life and fatigue crack propagation have been documented to some extent. [25] and [32] found surface defects on a similar FSW joint that may have diminished the fatigue strength. [33] found that surface defects played a significant role in the crack initiation stage. [34] and [35] observed that the zig-zag defect of FSW joints also known as joint line remnant acted as a crack initiation site during fatigue tests diminishing the fatigue life compared to sound welds. [36] observed that that the kissing bond defect on a similar aluminium FSW joint shorten the overall fatigue life of the specimen by favouring the the link between two cracks. A considerable understanding of the role of defects on the fatigue crack propagation mechanisms of FSW joints can be found in literature whilst the defects' effects on the fatigue crack initiation and propagation mechanisms of $L F W$ joints seem poorly documented.

A certain agreement about the presence of residual stresses in LFW joints can be found in literature [37, 38]. Compared to the parent material, LFW joints exhibit a reduced fatigue lifetime due to the presence of tensile residual stresses [39]. [38] have studied similar Ti6242 and TA6V LFW joints and reported that residual stresses decrease with increasing forging pressure. Despite these evidences, little research has been carried out on the relationship between the fatigue strength and the residual stresses for LFW welds.

In this paper, strength and fatigue strength of the little studied similar Ti6242 LFW joint are studied. The originality of this work relies on three major highlights. Firstly, the presence of defects at the microscopic scale has been assessed using non-destructive observations techniques such as synchrotron laminography. Secondly, a new analysis of the strain fields obtained by DIC has been proposed. Normalized strain rate spatio-temporal graphs were used to detect an early plastic activity in the surroundings of the WCZ and to foresee the fatigue crack initiation site on the welded structure. Finally, the fatigue life scatter and fatigue crack propagations mechanisms are studied. In particular, the effect of the workpiece surface contamination prior to welding on fatigue life has been assessed. In the experimental part, materials, welds and experimental details will be given. In the following section, results will be given in terms of weld microstructure, defects analysis, tensile tests on smooth specimens with additional DIC analysis. In particular, the normalized DIC strain rate fields are analysed to get insight about the potential fatigue crack initiation site. In the last part, the results of an S-N fatigue approach are presented. Particular attention is drawn to fatigue crack initiation sites and fatigue crack initiation mechanisms and their resulting fatigue scatter. The results and in particular the effect of defects is discussed. 


\section{Experimental and materials}

Parent material (PM) $\mathrm{Ti}-6 \mathrm{Al}-2 \mathrm{Sn}-4 \mathrm{Zr}-2 \mathrm{Mo}-0.1 \mathrm{Si}$ titanium alloy was used as $\mathrm{PM}$ in this study. Ti6242 is a near- $\alpha$ alloy with a $\beta$ matrix (b.c.c.) and $\alpha$ grains (h.c.p.). The nominal chemical composition is exhibited in Table 1. Billets of a $250 \mathrm{~mm}$ diameter produced by Timet were forged in the $\alpha+\beta$ domain. Blocks with $80 \mathrm{~mm} \times 70 \mathrm{~mm} \times 15 \mathrm{~mm}$ dimensions have been machined using Electrical Discharge Machine (EDM) for LFW. The long and short direction coincided with the rolling direction (RD) and transverse direction (TD) of the billet, respectively. The EDM cutting tool was a brass wire composed of Zinc and Copper.

\begin{tabular}{ccccc}
$\mathrm{Al}$ & $\mathrm{Sn}$ & $\mathrm{Zr}$ & $\mathrm{Mo}$ & $\mathrm{Si}$ \\
\hline 6 & 2 & 4 & 2 & 0.1
\end{tabular}

Table 1: Nominal chemical composition (\%wt.) of the Parent Material.

Linear Friction Welds Similar Ti6242 LFW joints were produced by ACB. During joining, friction occurred along the $F$ axis and a forging pressure was applied along the $P$ axis, as shown in Fig.1. $F$ and $P$ axes were parallel to the long and short directions of the blocks, respectively. The third direction corresponds to the thickness $(T)$. All specimens were machined by EDM parallel to a $P T$ plane and tested in the as welded condition (See Fig.2). A burn-off of about $2.76 \mathrm{~mm}$ was achieved.

Microscopic observations The samples were prepared by standard metallographic procedure consisting in mounting, grinding and polishing to a mirror like quality. The parent material and welded joint were observed in a ZEISS DSM982 Gemini Scanning Electron Microscope (SEM) operated at $15 \mathrm{keV}$ using backscattered electrons (BSE) detector. The fractographic analysis was carried out at low and high magnification using secondary electron detector in both LEO 1450VP SEM and ZEISS DSM982 Gemini SEM.

Laminography A $500 \mu \mathrm{m}$ thick sheet-like specimen parallel to a the $P T$ plane was machined, as shown in Fig.2. Laminographic observations were performed at the European Synchrotron Radiation Facility (ESRF) on the beamline ID19. A monochromatic beam of $36 \mathrm{keV} x$-ray energy was used to observe a volume of $1664 \mu \mathrm{m} \times 1664 \mu \mathrm{m} \times 500 \mu \mathrm{m}$. Voxel size was $0.65 \mu \mathrm{m}$ resulting in a final reconstructed volume of size $2560 \mathrm{px} \times 2560 \mathrm{px} \times 770 \mathrm{px}$. The normal to the specimen surface and the axis of rotation held an angle of about $30^{\circ}$ to the x-ray beam.

Microhardness Vickers microhardness tests were carried out across the weld with a $100 \mu \mathrm{m}$ step size, a $500 \mathrm{~g}$ load and a dwell period of $15 \mathrm{~s}$. Test were conducted following the ASTM E384-17 standard.

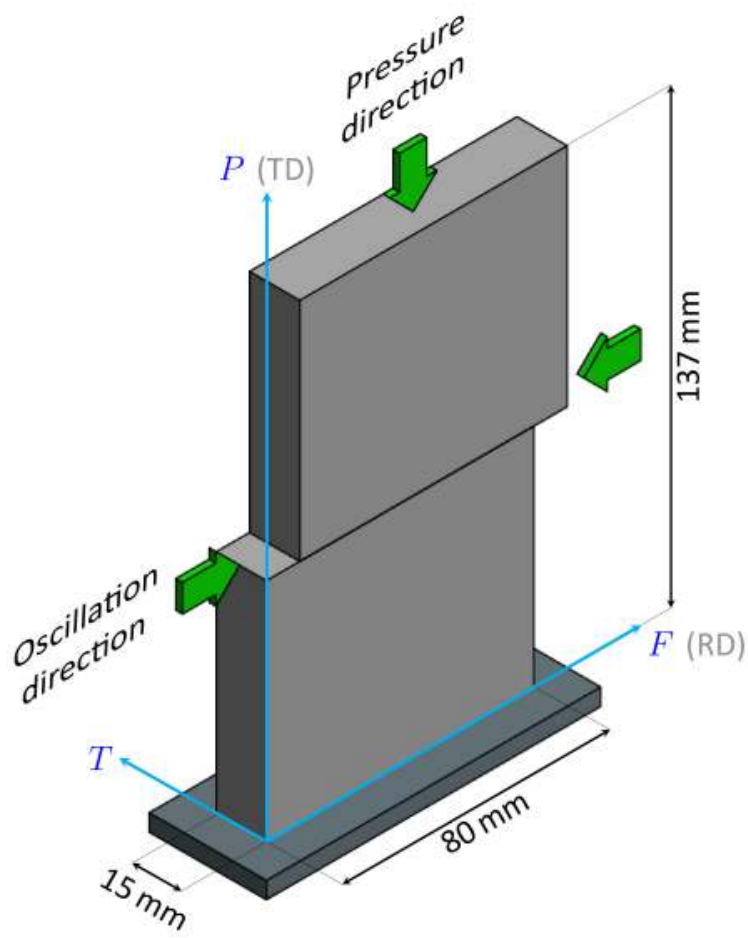

Figure 1: A schematic view of the welded joint showing the friction direction $(\mathrm{F})$, the forging pressure direction $(\mathrm{P})$ and the thickness direction $(\mathrm{T})$. 
Tensile test Nine smooth cross-weld specimens were machined. Four PM specimens and five cross-weld specimens were tested. Tensile tests were conducted following the ASTM-E8 standard with a MTS $250 \mathrm{kN}$ load frame at room temperature. Load frame cross-head speed was $0.032 \mathrm{~mm}$. The specimen geometry is shown in Fig.2. The tensile test specimens were machined parallel to a $P T$ plane and have been tested having the stationary workpiece on the upper grip of the load frame. Load was applied parallel to the $P$ direction. Elongation was measured with optical extensometers. Gage length was $25 \mathrm{~mm}$ and cross section was $3 \mathrm{~mm} \times 6 \mathrm{~mm}$.

Digital image stereo correlation During tensile test, weld zones local strain has been monitored using a standard system of Digital Image Stereo Correlation. A system of two $2048 \mathrm{px} \times 2048 \mathrm{px}$ Manta G-419B cameras was placed to follow the displacement of an artificial random black and white speckle depicted on the speci-

men surface (see Fig.3). The distance between the cameras was $a=26 \mathrm{~cm}$ and the camera-object distance was $b=31 \mathrm{~cm}$ (see Fig.3a), leading to a field of view of $40 \mathrm{~mm} \times 40 \mathrm{~mm}$. Images were exploited with Vic-3D ${ }^{\mathrm{TM}}$ from Correlated Solutions, Inc. (version 7.2.4, 2014). Acquisition was carried out taking 2 frames per second. Subset size was $35 \mathrm{px} \approx 175 \mu \mathrm{m}$, step size was $9 \mathrm{px}$ and filter size was $15 \mathrm{px}$. Before tensile testing, the displacement and the Hencky $\varepsilon_{\mathrm{PP}}$ measurements uncertainty were determined by correlating two consecutive images of the static specimen. Uncertainty in displacement measurements turned out to be $0.1 \mu \mathrm{m}$. This corresponds to a Hencky strain uncertainty of $\Delta \varepsilon_{\mathrm{PP}}=0.0002$ with a standard deviation of $\sigma_{\varepsilon_{\mathrm{PP}}}=9.56 \times 10^{-5} \%$. As shown is Fig. $3 \mathrm{~b}$, the load line, the specimen and the cameras frame were aligned using a laser level (red lines in Fig.3b). Both cameras were aligned to gravity using a water level.

a)

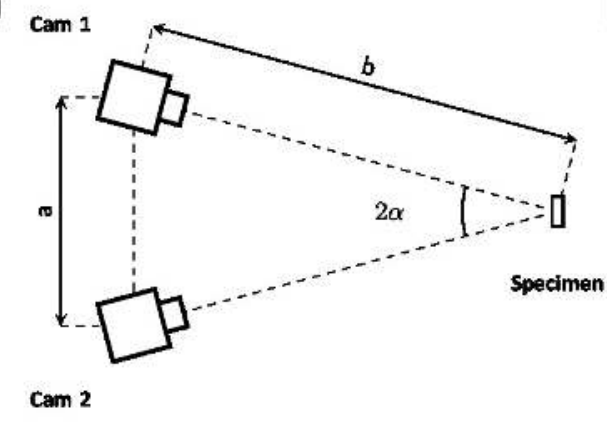

b)

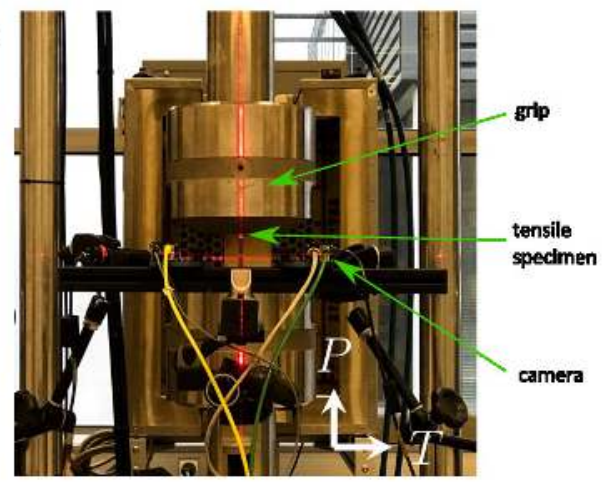

Figure 3: a) Schematic top view of the experimental setup for performing stereo correlation with a standard DIC system. b) Specimen, camera frame and load line aligned to gravity using a laser level (red laser lines). 
Fatigue test Standard fatigue test using smooth specimens have been carried out following the ASTM 466-07 standard. Two sets of specimens have been tested: fatigue specimens made of parent material and cross-weld specimens. PM samples have been machined in a perpendicular plane to the extrusion axis of the billet having its principal axis tangential to the billet section. Cross-weld specimens were machined parallel to a $P T$ plane of the joint, having its principal axis parallel to the $\mathrm{P}$ direction, as shown in Fig.2. Cross-weld samples have been labelled from 1 to 7 , being 1 the one on the centre of welded joint. The uniaxial tension zone had a length of $21 \mathrm{~mm}$ and a constant gage section of $3 \mathrm{~mm} \times 7 \mathrm{~mm}$. A sinusoidal waveform was imposed using a MTS $250 \mathrm{kN}$ servo-hydraulic load frame. The stress ratio was $R=0.1$ and the test frequency was $20 \mathrm{~Hz}$. Specimens corners were rounded with a lime and their surface were polished to a mirror-like state. Targeted fatigue life was $N_{f}=10^{5}$ cycles.

\section{Results}

\subsection{Microstructure}

Fig.4a shows a micrograph obtained using BSE detector for the PM. One can see that the microstructure consists of equiaxed $\alpha$ grains and lamellar $\alpha$ situated in a $\beta$ matrix. The Average Grain Intercept method was performed using BSE images of the PM microstructure (not shown here) to compute the average grain size of the $\alpha$ grains. The resulting average grain size was about $10.7 \mu \mathrm{m}$. Fig. $4 \mathrm{~b}$ shows the microstructure observed in the cross section of the welded joint on a PT plane. The presence of the $\mathrm{WCZ}$ is observed within the horizontal $\sim 100 \mu \mathrm{m}$ thick band. Microstructure in the surroundings of the WCZ shows indications of strong levels of plastic deformation and the fragmentation of former $\alpha$ grains. The level of plastic deformation is higher close the WCZ. Fig.4c shows a high magnification view of the WCZ. A very fine recrystallization is observed. Needle shape like grains of $\sim 150 \mathrm{~nm}$ thickness are observed. An acicular entangled $\alpha^{\prime}$ martensite is formed within prior- $\beta$ RX grains [40]. This microstructure is comparable to the one observed in TA6V and IMI-834 similar LFW joints found in literature [20,41]. Enhanced UTS is expected to be found in the WCZ.

a)

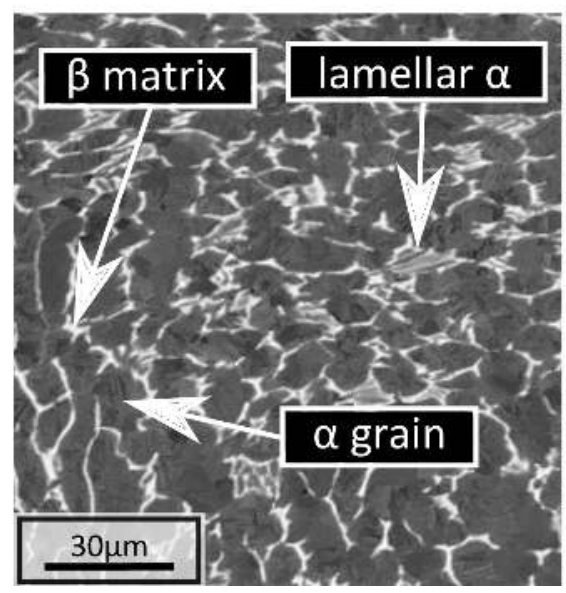

b)

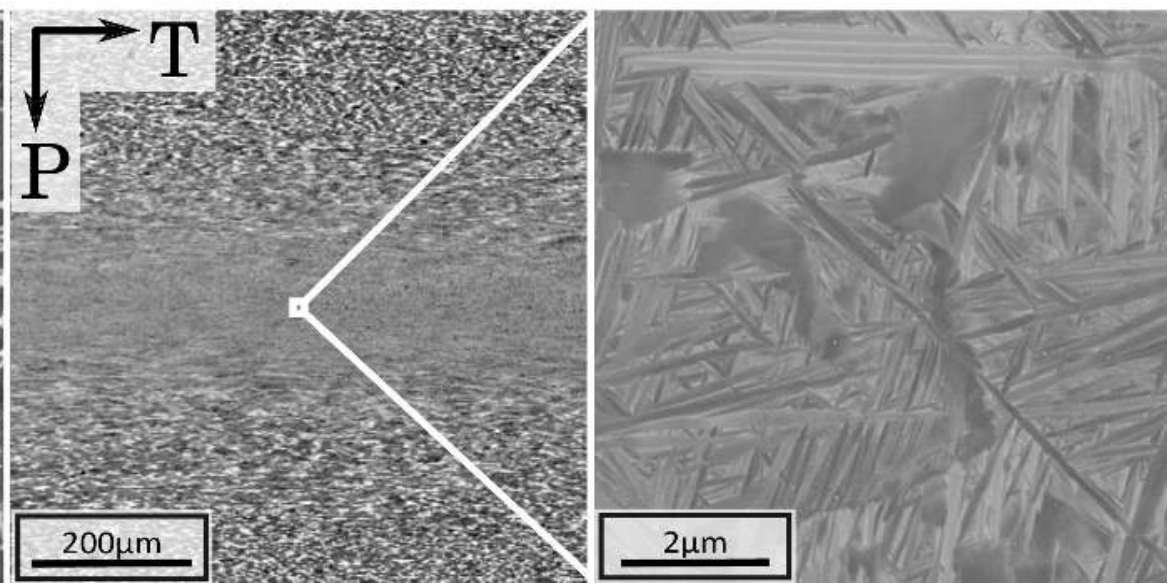

Figure 4: SEM Backscattered electron micrograph of the a) PM , b) affected zone containing the WCZ and the TMAZ and c) the very fine entangled acicular $\alpha^{\prime}$ martensite on the WCZ.

\subsection{Defects observation}

Fig.5a shows a $2 D$ section parallel to a $P T$ plane taken from the 3D laminographic volume. In absoption laminography, contrast is mainly based on the mean atomic number of the observed object. Increasing mean atomic number leads to brighter gray levels. Ti6242 is two-phase titanium alloy. Aluminium content stabilizes 
the $\alpha$ phase increasing the $\beta$-transus temperature while molybdenum content stabilizes the $\beta$ phase decreasing the $\beta$-transus temperature. Tin and Zirconium are neutral elements and they can be found in solid solution in both phases. The equiaxed dark features represent the lighter aluminium rich $\alpha$ grains and the brighter features the heavier molybdenum rich $\beta$ matrix. The parent material microstructure is observed in Fig.5b. The absence of the brighter features in Fig.5c reveals the WCZ and thermo-mechanically affected zone. Fig.5d shows a very low atomic number object with a circular shape surrounded by a very bright white line in its border. This edge enhancement is known to be evidence of a strong phase contrast revealing interfaces between different microstructural entities [42, 43]. These findings suggests the presence of voids. Using image processing through Python scripts based on the pymicro library (http://github.com/heprom/pymicro), a 3D visualization of the voids population has been performed. A colour has been given to the cavities in the weld interface and all other features have been set in absolute transparency (see Fig.5). Voids typical diameter was $4 \mu \mathrm{m}$ and they were located at the blocks interface following lines perpendicular to the friction direction.
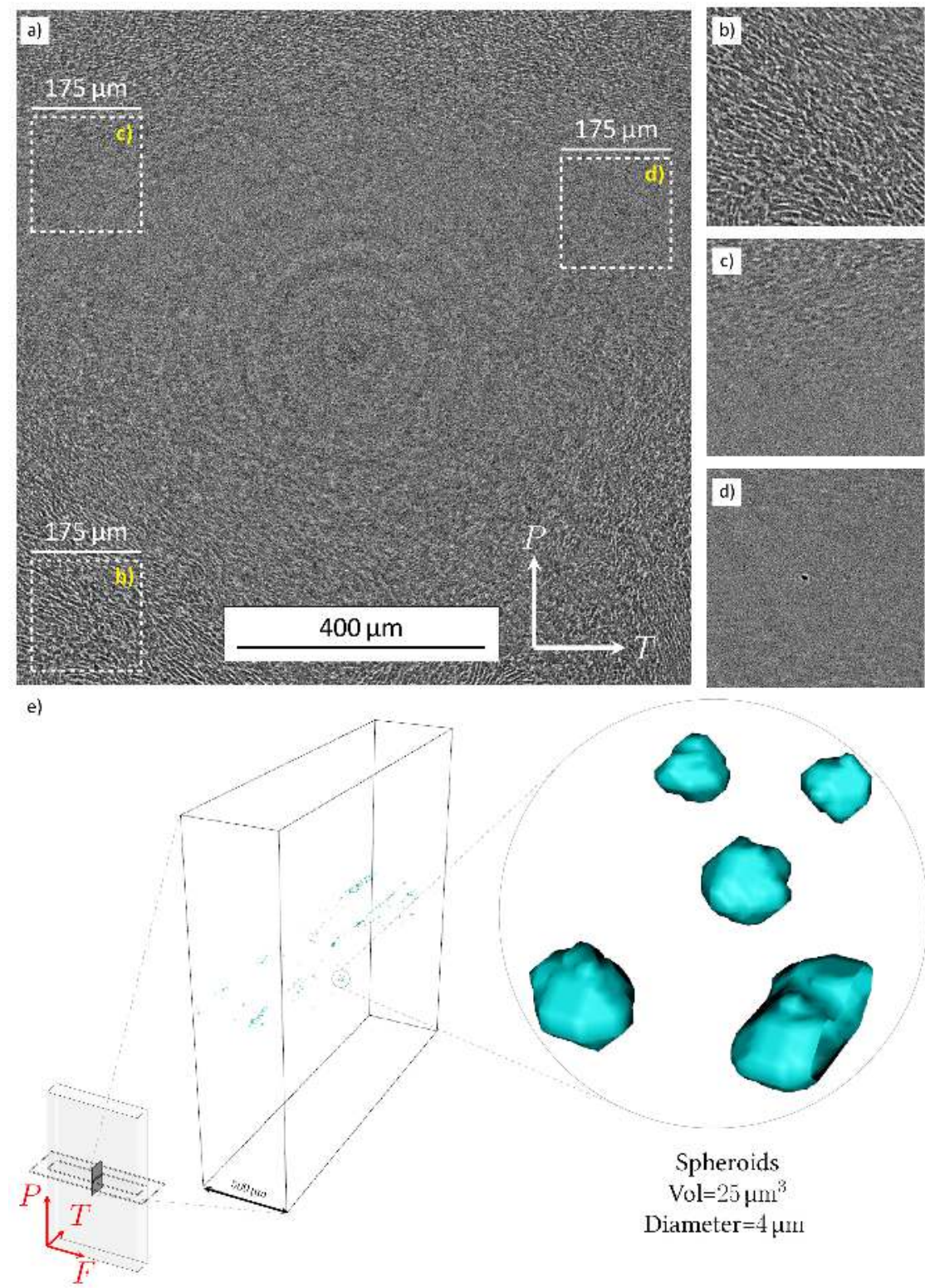

Figure 5: a) A $2 D$ view of a $P T$ section of the reconstructed laminographic volume. b) PM microstructure, $\alpha$ grains and the $\beta$ matrix are observed in the darker and brighter phases, recpectively. c) TMAZ. d) Cavities in the weld. e) $3 \mathrm{D}$ visualisation of the micrometric cavities population. 


\subsection{Microhardness evolution}

Fig.6 shows the average microhardness profile over three lines perpendicular to the WCZ. The measurement standard deviation for the three indentation lines is represented with vertical error bars. Microhardness showed a maximum of $420 \mathrm{HV}_{0.5}$ at the $\mathrm{WCZ}$ centre. Indentations further than $2.5 \mathrm{~mm}$ to the $\mathrm{WCZ}$ presented an average microhardness of $330 \mathrm{HV}_{0.5}$. Compared to the PM, microhardness on the WCZ is about $27 \%$ higher.

Standard deviation in microhardness measurement (see Fig.6) is strongly decreased in the WCZ which is consistent with a reduced grain size in this area. The increased microhardness at the WCZ is consistent with the formation of a meta-stable martensitic phases (see Section 3.1). The affected zone by the welding process can be estimated to be $5 \mathrm{~mm}$ wide. Increased microhardness on the WCZ suggests enhanced UTS. During tensile test, failure should thus take place on the PM.

\subsection{Tensile properties}

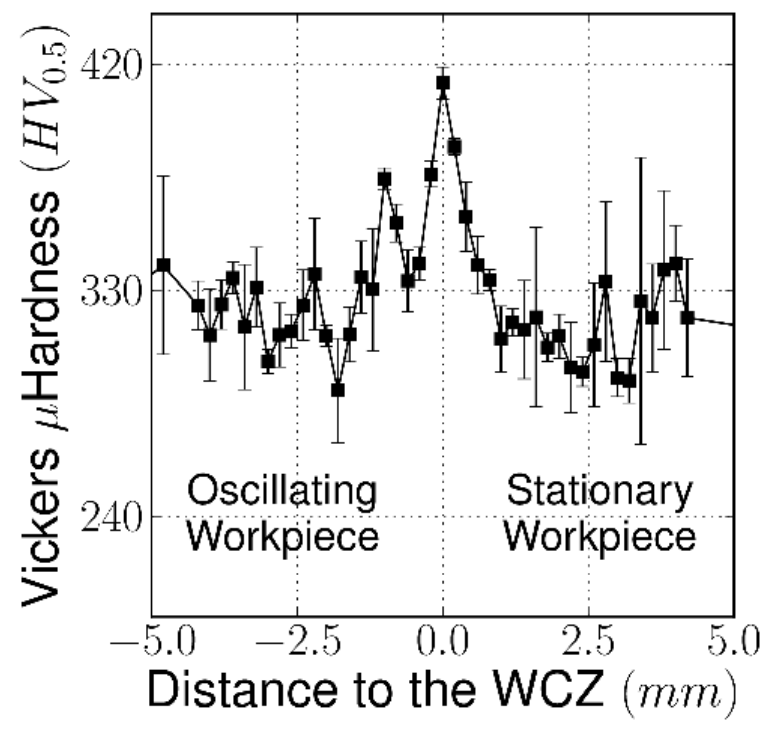

Figure 6: Mean Vickers microhardness over 3 profiles along the WCZ, having in vertical error bars the measurements standard deviation.

The macroscopic engineering stress-strain curves for the PM and cross-weld specimens are plotted in Fig.7a. Tensile test curves are plotted in gray for the PM specimens and in colours for the cross-weld specimens. The position on the welded joint of every cross-weld specimen is indicated in the overlaid schematic drawing of the welded block. Failure location for the cross-weld specimens is shown in Fig.7b. Average total strain measured over a $25 \mathrm{~mm}$ basis was $9.2 \%$ for the cross-weld specimens and $14.0 \%$ for the PM specimens. Young's modulus and UTS were respectively $E=118 \mathrm{GPa}$ and $U T S=960 \mathrm{MPa}$ for both sets of specimens with a very limited scatter. The mechanical resistance of the LFW joint showed a weld efficiency of $100 \%$.

All cross-weld specimens failed far from the WCZ in the oscillating work-piece side suggesting that the WCZ has a higher UTS (see Fig.7). These findings are in agreement with the increased microhardness measured in section 3.3, revealing a weld overmatch.

a)

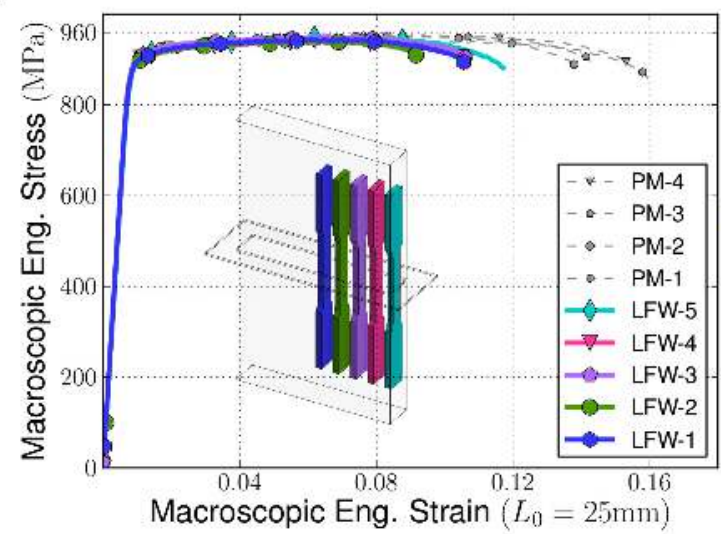

b)

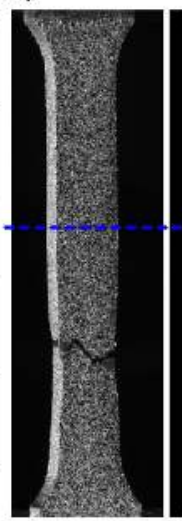

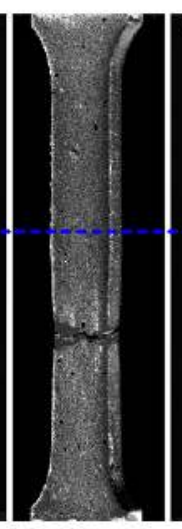
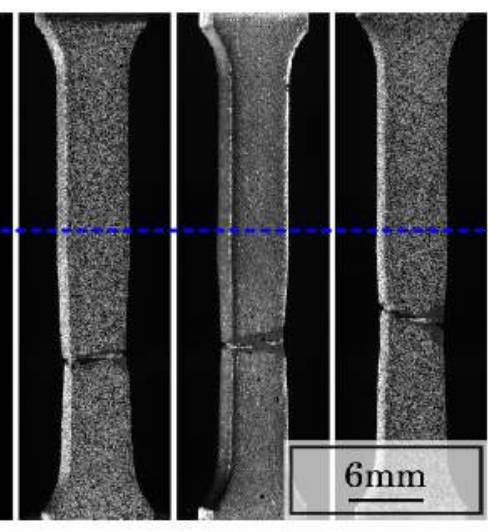

Stationary Workpiece

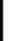
WCZ

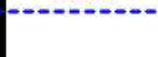

Oscillating Workpiece

Figure 7: a) Engineering strain-stress curves for the LFW cross-weld (colour) and PM specimens (gray) b) Macroscopic post mortem view of the LFW cross-weld specimens showing failure location. 


\subsection{DIC analysis}

\subsubsection{Cumulated strain}

Fig.8a shows the specimen and its black and white speckle to perform the local strain monitoring. The overlaid green rectangle in transparency depicts the region of interest (ROI for DIC). Fig.8b shows nine steps of the cumulated strain map within the ROI. The colour bar is shared with Fig.8c. To illustrate the temporal strain cumulation, the strain history of a generatrix line (vertical white line in Fig.8a is plotted in the so called spatiotemporal graph [44, 45, 46] of Fig.8c. Macroscopic strain and $\mathrm{P}$ coordinates are given in the horizontal and vertical axis, respectively. The mapped variable is the strain field following the load direction $\left(\varepsilon_{\mathrm{PP}}\right)$. The maximum strain level in the colour bar is set to the maximum local strain found during the test. The WCZ is placed at $0 \mathrm{~mm}$ of the $P$ coordinate. The oscillating workpiece side of the weld is placed in the negative values of the $P$ axis. The macroscopic engineering stress-strain curve is plotted in white. The nine strain maps of Fig.8b are taken in the nine characteristic instants (white squares) of the macroscopic engineering stress-strain curve of Fig.8c. Tensile tests give information about the macroscopic engineering stress and uniform strain for an uniaxial stress state up to necking. Given the heterogeneity of the welded structure, local information is required. The surface 3D displacement and 2D strain fields are obtained by Stereo Digital Image Correlation. Plastic strain for the PM is higher and slightly asymmetrical. Macroscopic engineering stress reaches the UTS at a macroscopic engineering strain of 0.08 . Afterwards, localization takes place at a distance of $10 \mathrm{~mm}$ in the oscillating workpiece side reaching a local strain of 0.36 .

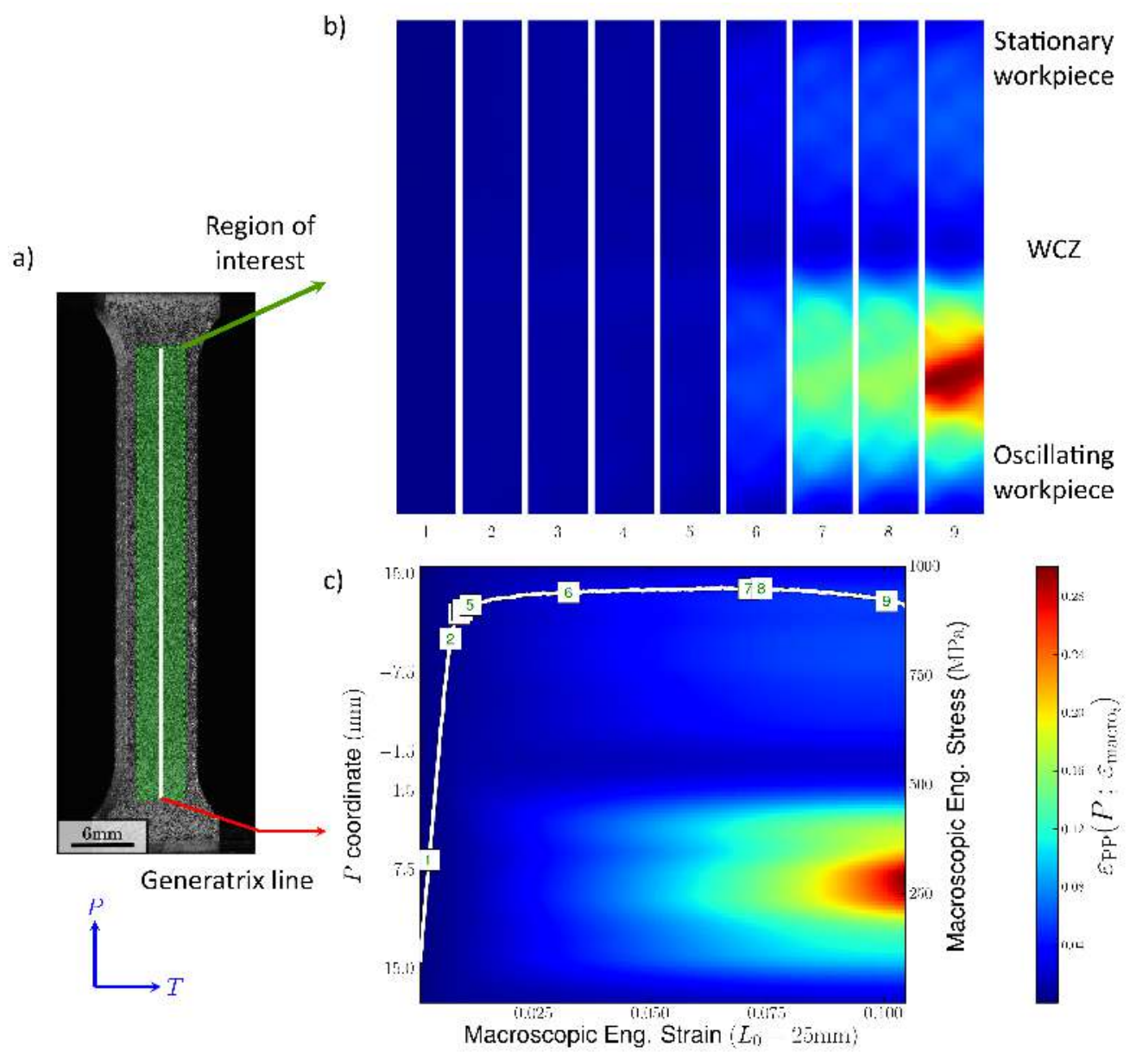

Figure 8: a) LFW cross-weld tensile specimen in the load frame showing the region of interest (ROI) (green rectangle) and a generatrix line (white line); b), nine steps of the strain field in the ROI; and c) a cumulated strain spatio-macroscopic deformation graph and the macroscopic engineering strain-stress curve. 


\subsubsection{Strain profiles}

To investigate further the heterogeneous strain distribution, Fig.9 shows the strain profiles for three cross-weld and one PM tensile test specimens at three different characteristic instants of the macroscopic tensile test curve: at yielding (dashed lines), at UTS (thin lines) and at failure (thick lines). Strain profiles at yielding show heterogeneous levels along the ROI. The strain profile at UTS for the PM sample is shown. The Failure strain profile for the PM sample shows the strain localization with a maximum local strain of 0.4 and a neck that affects $10 \mathrm{~mm}$ of the gage length. The PM in the cross-weld specimen showed a higher local strain than the WCZ for the strain profile at UTS. WCZ mean strain at UTS is 0.018. Localization takes place at PM on the oscillating workpiece side of the specimen at a distance of $10 \pm 2 \mathrm{~mm}$.

The homogeneity of the strain profiles at the yielding strength suggests that the WCZ Young's modulus is the comparable to the PM. Maximum local $\varepsilon_{\mathrm{PP}}$ strain at fracture was comparable between PM and the PM in the cross-weld specimens. No significant strain increment was observed for the WCZ between UTS and failure. First, it should be pointed out that the WCZ strain contribution to the cross-weld total macroscopic strain is lower that that of PM. Thus PM samples show a higher ductility, as pointed out in Section 3.4. Secondly, it would be interesting to determinate whether the WCZ has reached plasticity or not. Using Hooke's law and the values of E and UTS presented in Section 3.4, it could be calculated that the WCZ elastic strain was 0.008, which was smaller than the measured total strain. Hence, the WCZ had deformed plastically. Since the minimum strain was found at the WCZ, it could be concluded that plasticity takes places in the entire gage length. Understanding the chronological order of the plastic activity at the welding zones can be particularly relevant for the early stages of plasticity that govern low cycle fatigue behaviour.

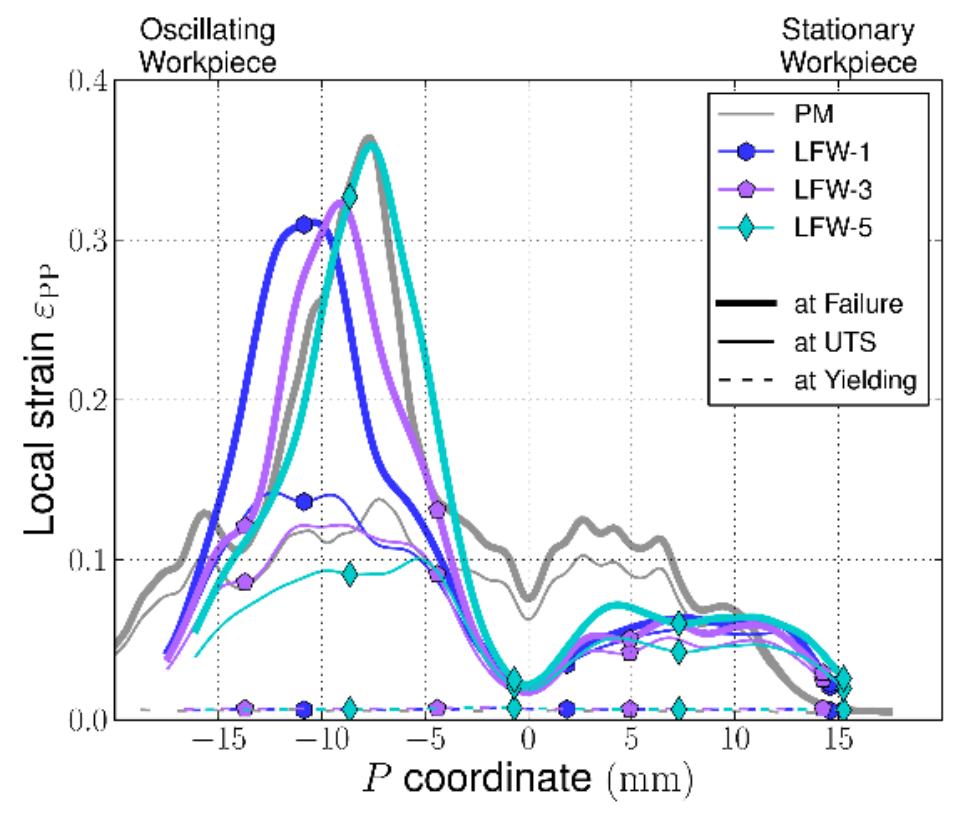

Figure 9: Strain profiles obtained by DIC for PM (gray) and LFW cross-weld (colours) tensile specimens at yielding, at UTS and at failure.

\subsubsection{Incremental strain}

Whilst in previous sections the total cumulated strain was investigated, here the instantaneous strain activity will be assessed. Fig.10a shows a view of the specimen surface showing its black and white speckle for DIC strain monitoring. In Fig.10b, the same nine instants as analyzed in Fig.8b-c are now analyzed in terms of incremental strain. This incremental strain $\Delta \varepsilon\left(t_{i}\right)$ for a given time interval $\Delta t_{i}$ is an approximate measure of the local strain rate for a given time $\dot{\varepsilon}\left(t_{i}\right)$. Given that the $\varepsilon\left(t_{i}\right)$ signal was weaker for the initial correlation steps, 
the measurement noise became comparable to the $\Delta \varepsilon\left(t_{i}\right)$ signal. Different time steps were taken to ensure the same signal-noise ratio: $\Delta t_{i}=2000 \mathrm{~ms}$ for the elastic domain and $\Delta t_{i}=500 \mathrm{~ms}$ for the plastic domain. Notice that the strain rate over the generatrix line has been normalized by the maximum strain rate found on the line for a given $t_{i}$. Consequently, the colour bar has been scaled from 0 to 1 . This information permits the instantaneous maximum strain rate to be followed. Fig.10b and Fig.10c share the colour bar.

The macroscopic engineering stress-strain curve was linear and the normalized strain rate map was homogeneous until $\varepsilon_{\mathrm{PP}}^{\text {macro }} \sim 0.0065$. The second map has been taken at the beginning of the non-linearity of the macroscopic engineering stress-strain indicating the onset of plasticity. Some localized plastic activity is observed in the vicinity of the WCZ $(P=1.5 \mathrm{~mm})$. The strain rate maps 3 to 9 shows that plastic activity shifted from the WCZ to the oscillating workpiece side. Fig.10c shows that the maximum strain rate shifted from the WCZ to the PM where final localization took place, leading to failure. The most astonishing fact is that, even if failure takes place far from the WCZ, plastic activity initiates at its vicinity despite the weld overmatch. This behaviour could be linked to the presence of residual stresses [37, 38, 47]. Fatigue failure is known to initiate where the first stages of plastic activity take place. Therefore, fatigue crack initiation should take place in the vicinity of the WCZ.

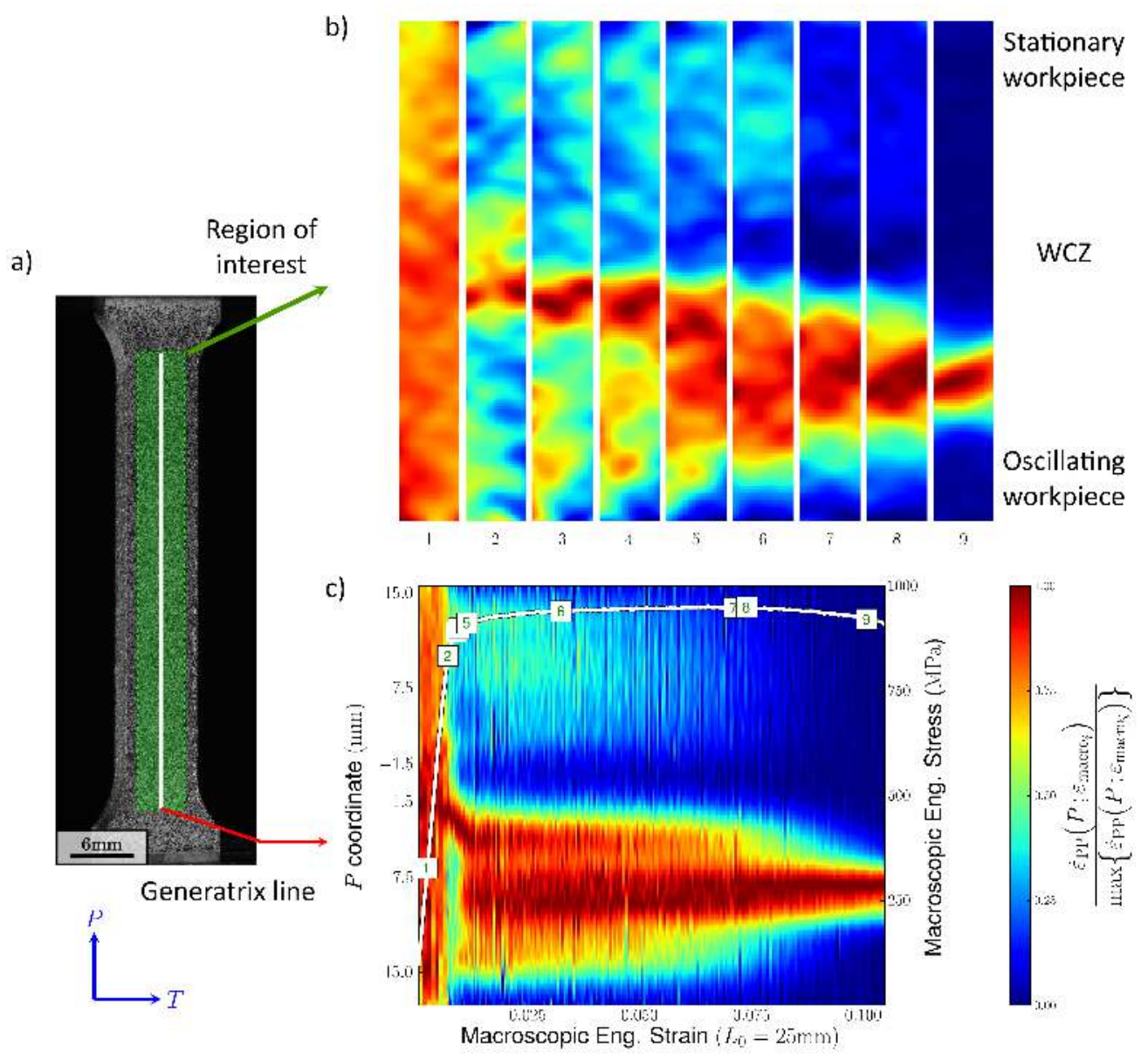

Figure 10: a) LFW cross-weld tensile specimen in the load frame showing the ROI (green rectangle) and a generatrix line (white line); b) nine steps of the instantaneously normalized strain rate field in the ROI; and c) a normalized strain rate spatio-macroscopic deformation graph with the overlaid macroscopic engineering strain-stress curve. 


\subsection{Fatigue}

\subsubsection{Wöhler curves}

Fig.11 shows the S-N curve for the PM fatigue specimens (white triangles) and the cross-weld fatigue specimens (yellow triangles) specimens. For the sake of simplicity, only the LFW-1 and LFW-3 fatigue specimens have their label next to its marker on the S-N curve. For the target fatigue life of $10^{5}$ cycles, fatigue strength of PM and LFW joint are $\sim 600 \mathrm{MPa}$ and $\sim 625 \mathrm{MPa}$, respectively. The LFW-1 and LFW-3 fatigue specimens were both tested at a maximum stress of $500 \mathrm{MPa}$. Compared to the PM samples, fatigue resistance of cross-weld specimens is slightly reduced. However, cross-weld specimens present significant fatigue life scatter.

\subsubsection{Crack initiation site}

The specimen surface parallel to the $P T$ plane has been observed post-mortem using BSE detector for five cross-weld fatigue specimens. Fig.12 shows the distance between the crack initiation site and the WCZ for five cross-weld fatigue specimens. The WCZ of every specimen has been aligned to the vertical green dashed line on the right. Red crosses

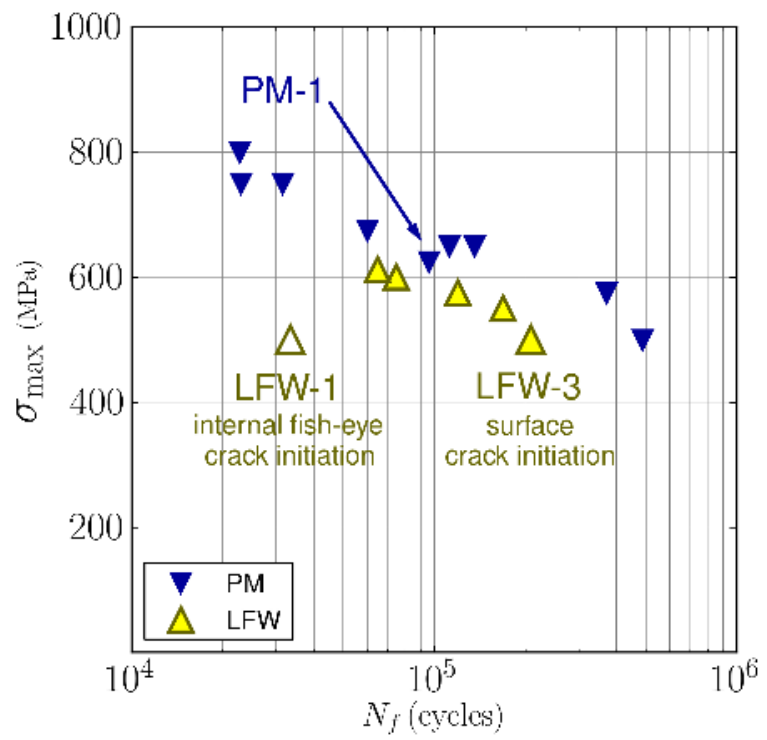

Figure 11: S-N curve for the PM (blue) and LFW cross-weld (yellow) fatigue specimens $(R=0.1)$. indicate the crack initiation site for every specimen. The LFW-1 fatigue specimen presented its crack initiation site at the WCZ. The distance from the WCZ to the crack initiation site for the cross-weld fatigue specimens $(i=2,3,4,5)$ specimens occurred at a mean distance of $1.5 \mathrm{~mm}$. The LFW-6 fatigue specimen failed at a distance of $2.8 \mathrm{~mm}$. As anticipated in Section 3.5.3, all cross-weld specimens had its fatigue crack initiation in the vicinity of the weld possibly due to the presence of residual stresses $[38,37]$.

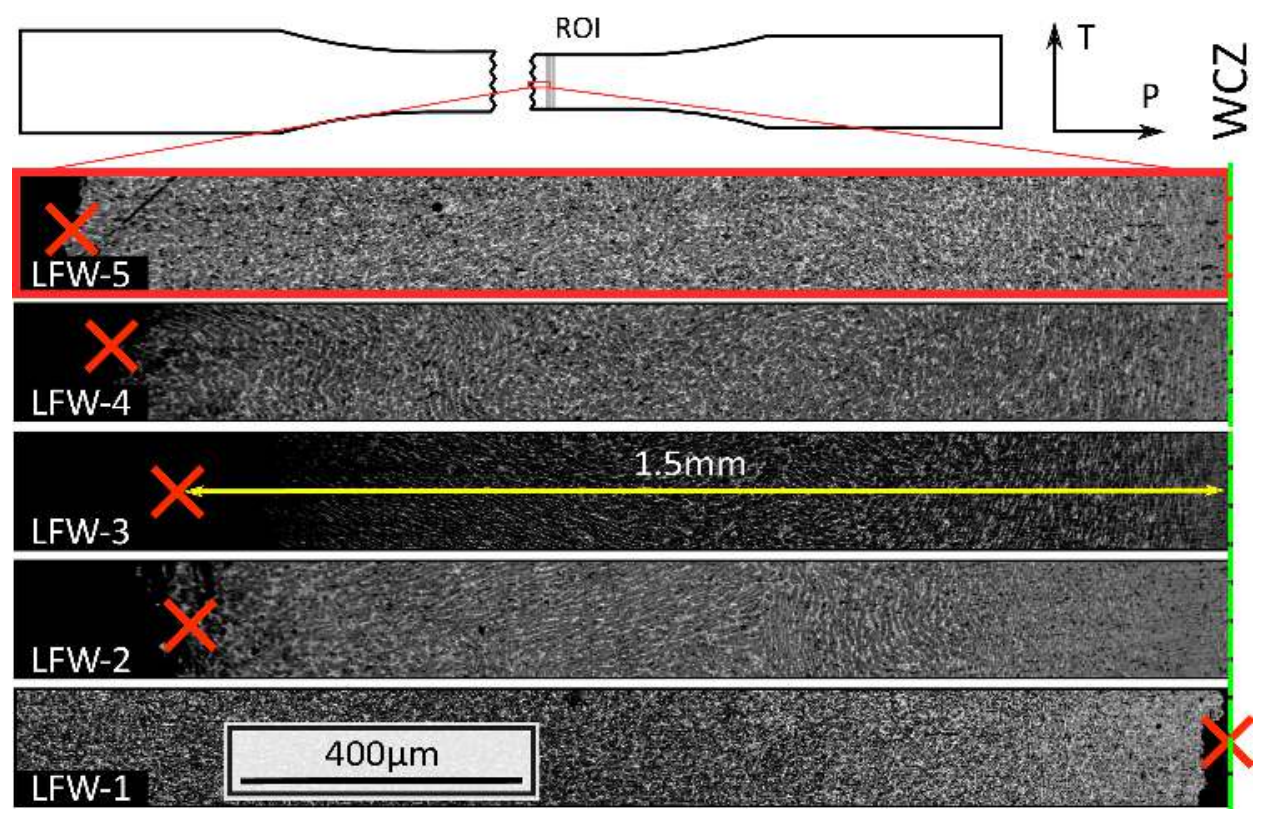

Figure 12: Post mortem backscattered electron view of the specimen surface on a $P T$ plane showing with a red cross the failure location and its distance to the WCZ for five LFW cross-weld fatigue specimens. 


\subsection{Fractographic observations}

The fatigue crack propagation mechanisms of the PM and LFW cross-weld fatigue specimens are studied through SEM and BSE fractographic observations of the PM-1, LFW-1 and LFW-3 fatigue specimens fracture surfaces. Surface crack initiation site of the PM-1 fatigue specimen is shown in Fig.13a-b. Long fatigue crack propagation ridges converge to a point at the specimen surface. Fig.13c and Fig.13d show respectively a SEM and BSE high magnification view of the crack initiation site. Features of a comparable size to the PM underlying microstructure, i.e. $\alpha$ grains, are seen. The orientation of the crack propagation plane seems to change at the boundaries of $\alpha$ grains. The crystallographic facets indicate a stage I fatigue initiation mechanism for the PM.

Figs.14a-b show the surface crack initiation site of the LFW-3 fatigue specimen. The fracture surface is located at a distance of $\sim 1.5 \mathrm{~mm}$ from the $\mathrm{WCZ}$ as shown in Fig.12. Several fatigue ridges converge to a region at the specimen surface. Following the zoom of Fig.14b, it seems that the crack initiated at several closely spaced sites. Figs.14c-d show a SEM and BSE high magnification micrograph of the central crack initiation site, respectively. Three features resembling to $\mathrm{PM} \alpha$ grains are seen. A stage I fatigue crack propagation similar to the PM is observed. This is consistent with the fact that microstructure similar to the PM is found this location. However, it seems that the residual stresses in this location, as registered by [37,38, 47], were sufficient to trigger the onset of plastic activity in several sites of this area.

a)
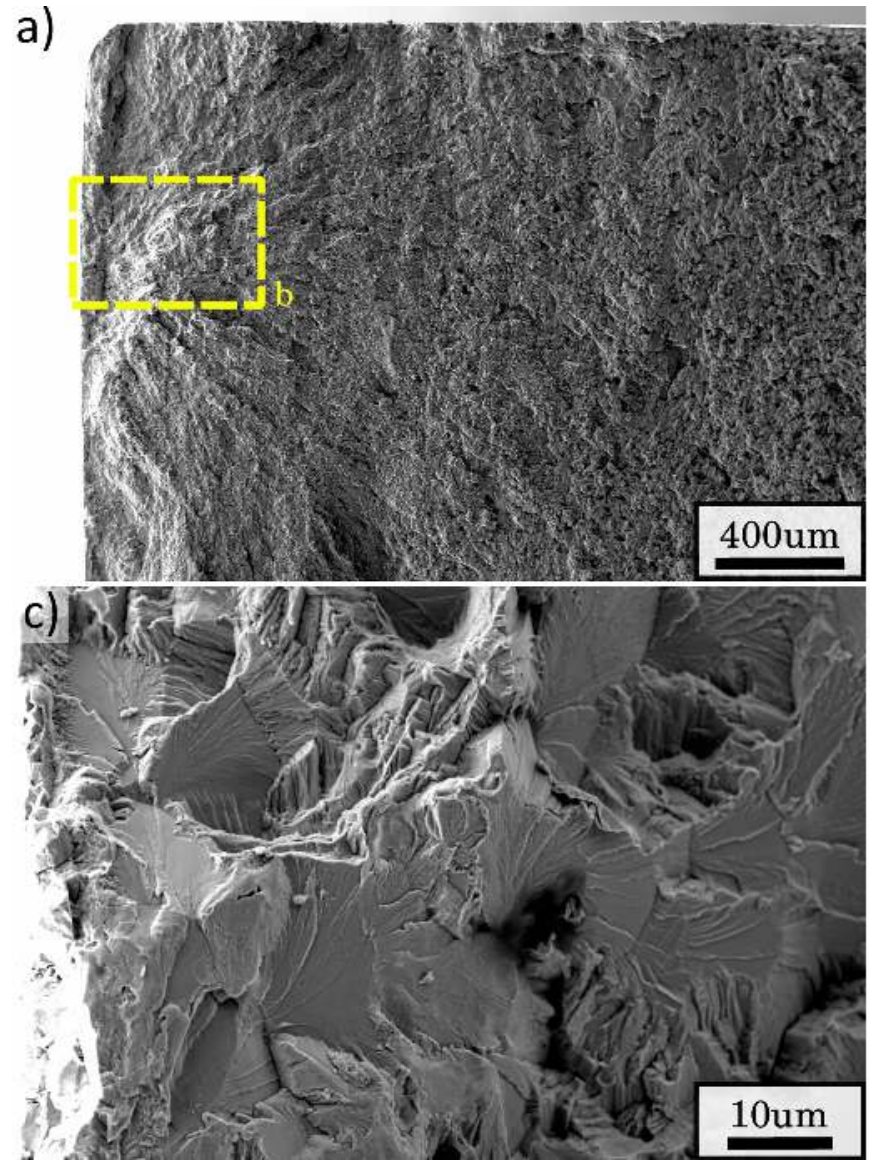
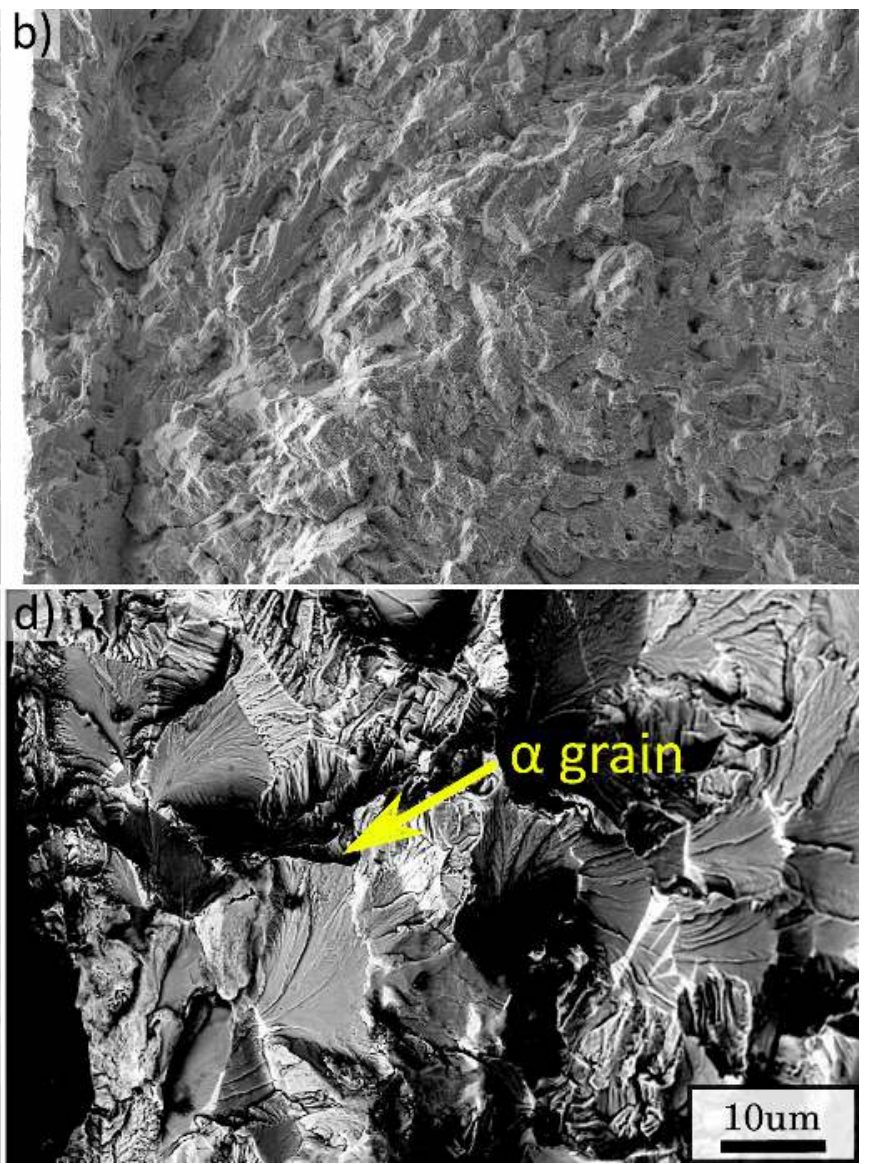

Figure 13: Fractograph of the PM-1 fatigue specimen, showing a) fracture surface; b) low magnification micrograph of the crack initiation site; c) SEM high magnification observation; and d) BSE observation of the crack initiation site. 


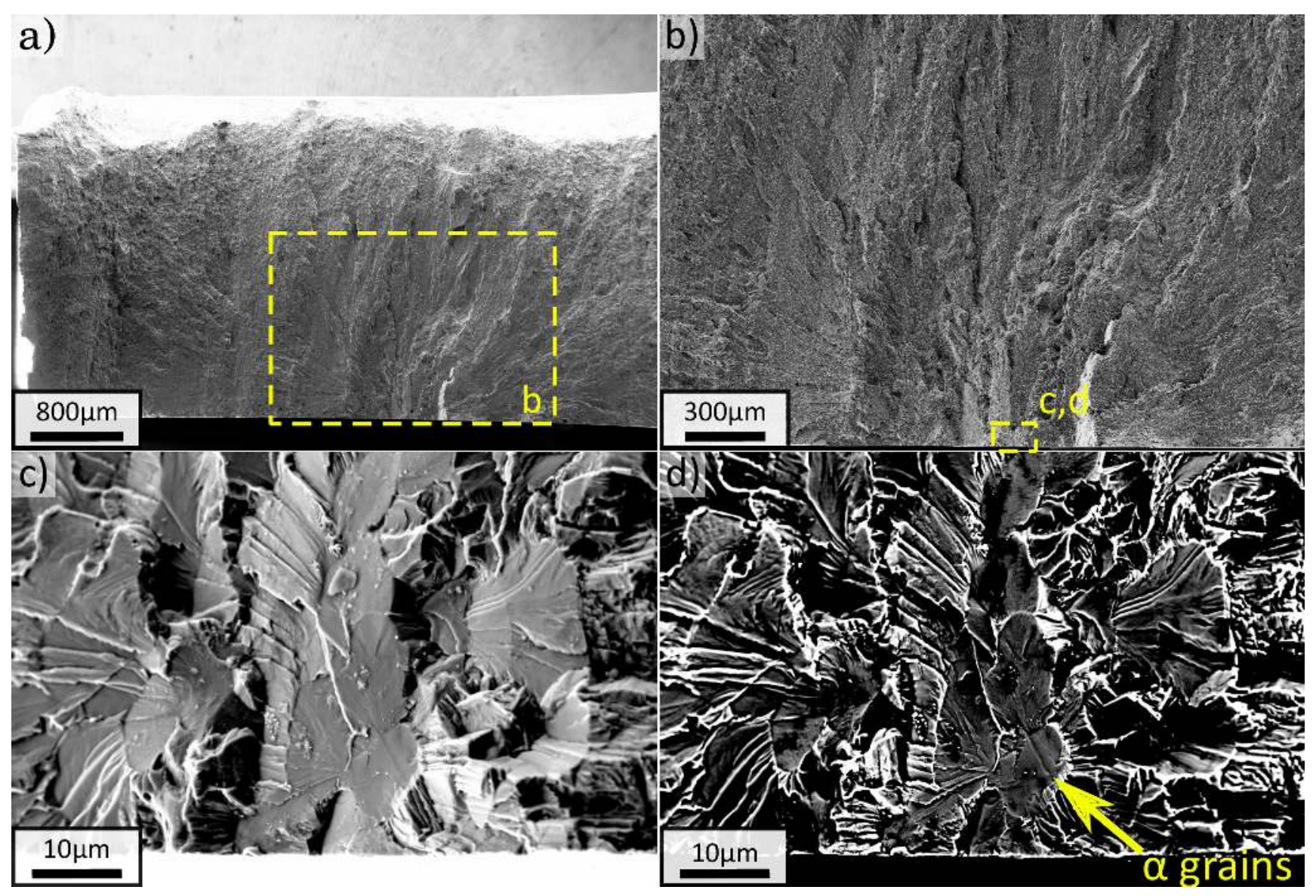

Figure 14: Fractograph of the LFW-3 fatigue specimen, showing a) fracture surface; b) SEM low magnification micrograph of the crack initiation site; c) SEM high magnification observation; and d) BSE observation of the crack initiation.

\subsubsection{Defect induced internal crack initiation}

Fig.15a shows the fracture surface of the short fatigue life LFW-1 fatigue specimen. Fatigue ridges converge to a line in the centre. Up to the dashed green line, the surface roughness around the fatigue ridges was smooth; afterwards, surface became rougher. It seems that fatigue crack propagation happened in vacuum up to the point it reached the specimen surface allowing the air to enter. The entering air may have changed the surface roughness during fatigue crack growth, due to the influence of oxidation layers in the crack tip (see Fig.16e). This phenomena is known as 'fish-eye' and has already been documented for martensitic steel by ([48, 49, 50]). A high magnification image at the centre of the central line is shown in Fig.15b. Three main features are observed: gray round-cornered features resembling to dendrites (see Figs.16a-c), a population of nanometric black voids and flat surfaces reminding cleavage facets (see Fig.16b). It should be recalled that the LFW-1 fatigue specimen had its fatigue crack initiation site in the WCZ (see Fig.12) and that the microstructure in this location is typically an acicular entangled $\alpha^{\prime}$ martensite (see Fig.4). In constrast, the round-cornered features seen in Figs.16a-c are very different from the underlying microstructure in this location. These features resemble to dendrites as e.g. described by [51] and [52] and hence imply local melting of the material as will be discussed in Section 4. It seems that an internal crack was provoked during the first tensile cycle, due to a brittle fracture at the surroundings of dendritic defects. At the frontier of the internal cleavage crack, the failure surface convey the impression of the martensitic lath of the underlying microstructure (see Figs.4c and 16d). Seemingly, a crystallographic fatigue crack propagation occurred corresponding to stage I-like fatigue crack propagation at low levels of stress intensity factor and small plastic zones sizes. This phenomena has been approached elsewhere $([50,53])$. The 
final ductile rupture mechanisms are put in evidence by the dimples of Fig.16f. A better understanding about the origin of these dendritic defects and the internal cleavage crack is required.
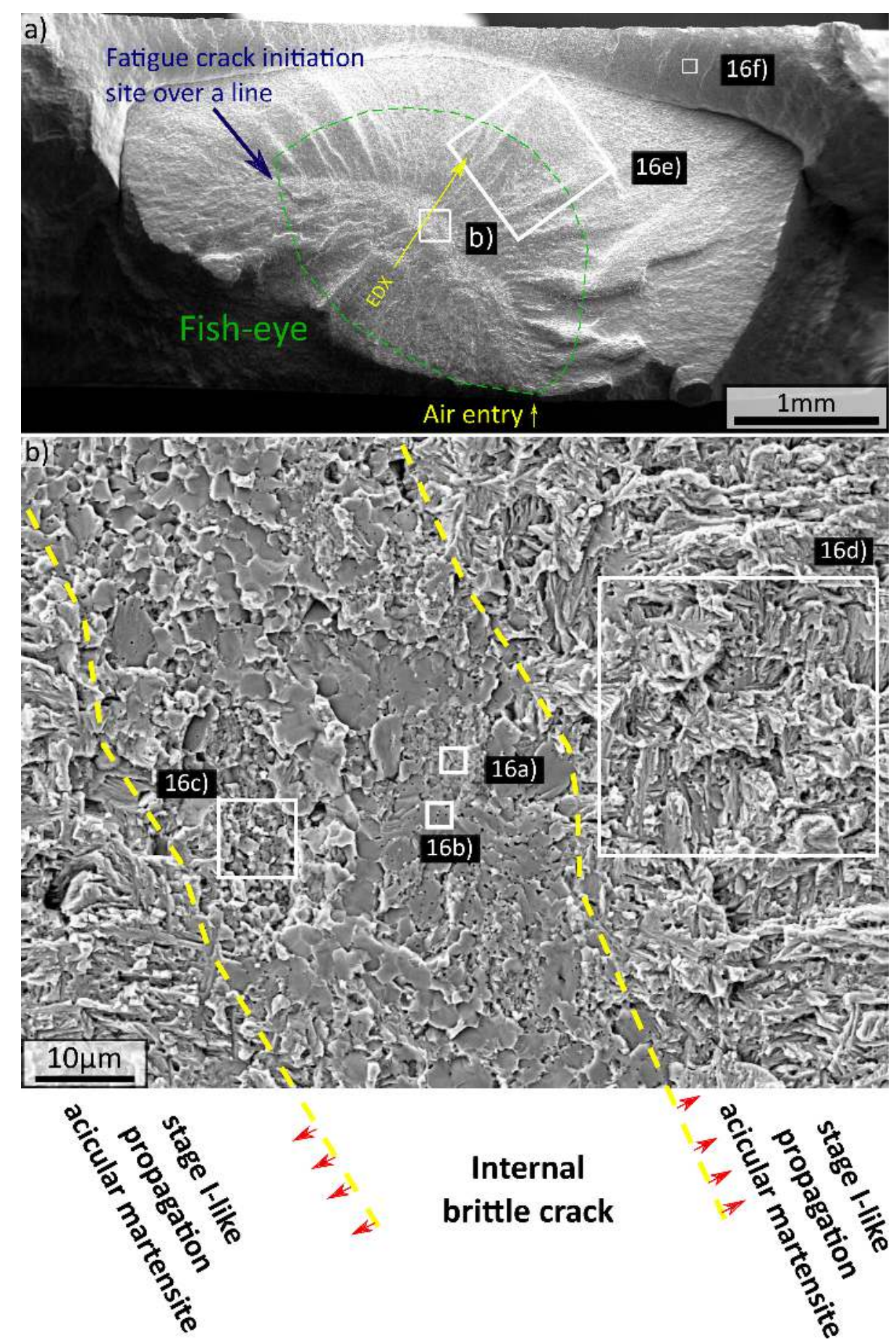

Figure 15: a) Fractograph of the LFW-1 fatigue specimen showing the internal crack; b) High magnification fractograph of the internal crack showing dendritic defects and first stages of the crystallographic stage I-like fatigue propagation. Region of interests (ROIs) of Fig.16 are indicated by white rectangles. 


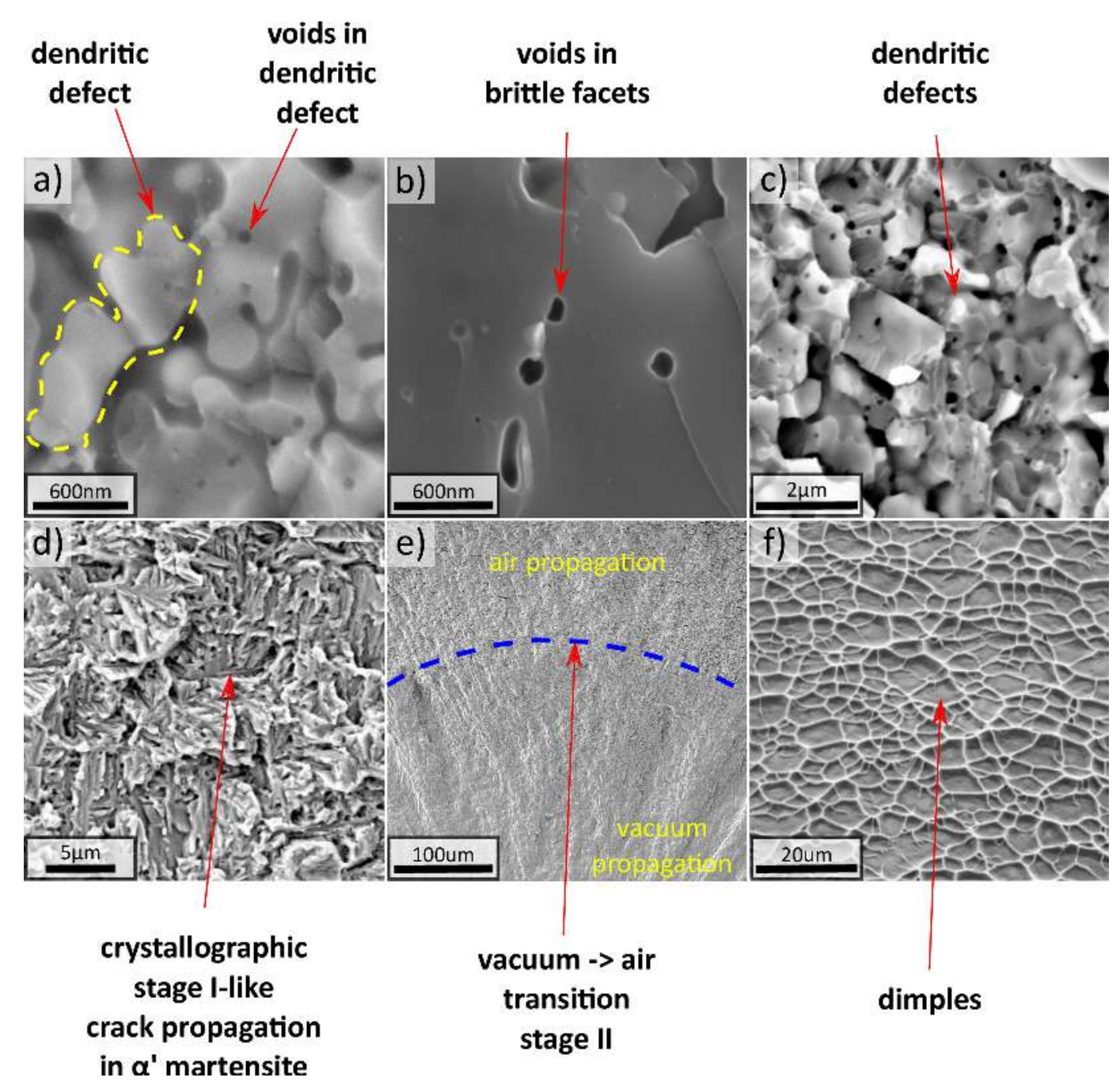

Figure 16: a) Fractographs of the LFW-1 fatigue specimen showing a) dendritic defect; b) brittle facets; c) dendritic defects; d) crystallographic stage I-like crack propagation in $\alpha^{\prime}$ martensite; e) transition of crack propagation in vacuum/air; f) dimples showing the final ductile fracture. 


\subsection{Chemical Analysis}

A chemical analysis was performed over the fracture surface of the LFW-1 fatigue specimen to get a better understanding on the origin of fatigue crack initiation site. A view of the internal fatigue crack initiation site is shown in Fig.17b. The red line shows the curvilinear path on which a EDX analysis has been performed. It should be noted that at the coordinate $\sim 400 \mu \mathrm{m}$ of the analyzed path, the dendritic defect shown of Fig.16a is located. In this analysis, all elements on Table 1 plus two extra elements not present in the PM composition have been indexed: $\mathrm{Cu}$ and $\mathrm{Zn}$. These elements are present in the cutting tool as described in Section 2. Fig.17b shows the weight percentage of $\mathrm{Cu}$ and $\mathrm{Zn}$ over the red line of Fig.17a. A maximum of $5 \%$ wt. $\mathrm{Cu}$ is found for the coordinate $388 \mu \mathrm{m}$. A maximum of $3 \% w t$. $\mathrm{Zn}$ is find for the coordinate $913 \mu \mathrm{m}$. a)

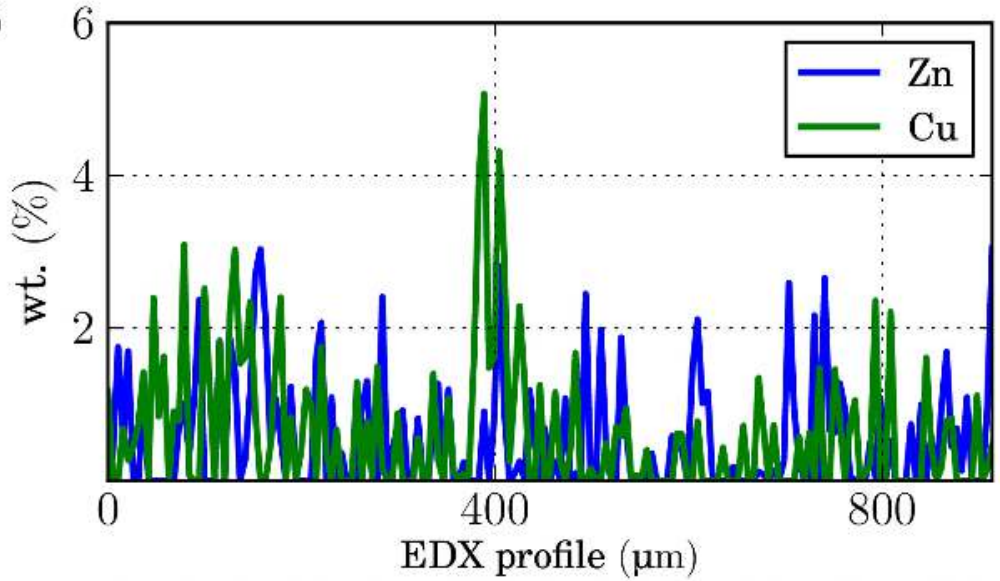

b)

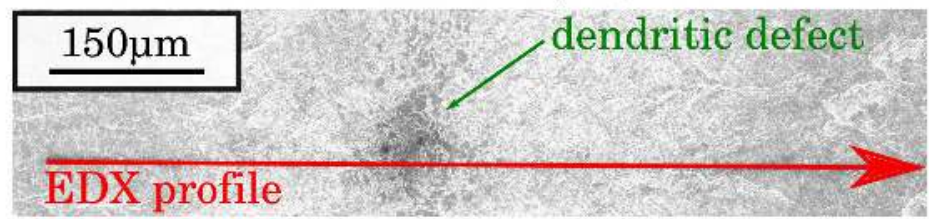

Figure 17: a) $\mathrm{Zn}$ and $\mathrm{Cu}$ profile indexation of an EDX analysis over the red path of Fig.17b and b) fractograph of the LFW-1 fatigue specimen showing the EDX profile of Figure Fig.17a (red line).

\section{Discussion}

The microstructure observed at the $\mathrm{WCZ}$ and the monotonic mechanical properties of the studied joint have shown a strong agreement with available research in literature on similar LFW joints made of comparable Ti alloys $[20,41]$. The quality of the studied weld in terms of UTS, ductility and burn-off is satisfactory. In terms of presence of defects and cyclic properties, it is more compromising.

Origin of defects. In Section 3.8, the presence of $\mathrm{Cu}-\mathrm{Zn}$ hot spots has been highlighted. From the present study the following scenario can be suggested. It is very likely that the observed brass contaminants were spread by the EDM cutting tool during the machining of the blocks prior to welding. [16] registered local temperature measurements during LFW of similar joint made of IMI-834 titanium alloy which is material comparable to the Ti6242 used in this study. The registered temperatures overreached $\sim 1000^{\circ} \mathrm{C}$ which is comparable to the melting point of a vast range of $\mathrm{Cu}-\mathrm{Zn}$ alloys [54]. These brass smeared hot spots may have melted and then further solidified favouring the apparition of dendrites and shrinkage voids (see Fig.16a-c). These kind of voids have already documented for casting alloys [52]. It may reasonably be assumed that the power input was enough to produce a weld overmatch but slightly insufficient to properly auto-clean the smeared weld interface leaving contaminants as suggested by [55]. A less likely hypothesis for the apparition of these voids may be related to the vaporisation of low melting point elements present in the weld interface. The presence of a Cu- $\mathrm{Zn}$ hot spots leads to localized melting of the bulk. In such conditions, the welding technique is no longer a solid-state joining process. To the author's knowledge, this phenomena has not been studied yet.

Another possible explanation to this phenomenon is the so called strain induced porosity. [56] and [57] have documented the apparition of void nucleation in microstructural phases boundary when loading two-phase 
titanium alloys under high temperature for certain levels of strain rates. The computation of the maximum strain rate using the weld parameters and the theoretical formula proposed by [7] turned out to be $\dot{\varepsilon}_{\max }=$ $\frac{a f}{L}=1.25 \mathrm{~s}^{-1}$. If this value, the temperature measured by [16] and the grain-boundary microcracking map proposed by [56] were taken into account, it appears that the strain induced porosity phenomenon might have occurred.

Two populations of nanometric and micrometric cavities have been observed in the non destructive observations and fractographs of Sections 3.2 and 3.6, respectively. Similar voids have already been observed elsewhere [26]. Nonetheless, their origin remains unexplained.

Fatigue crack initiation site and early plastic activity. Microhardness profiles and tensile test revealed that the $\mathrm{WCZ}$ and its vicinity have higher strength than the PM. An early plastic activity was however observed in the vicinity of the WCZ. The origin of this activity is of particular interest since it allowed the fatigue crack initiation site location to be predicted (see Section 3.5.3). Several authors have reported high levels of tensile residual stresses following the $\mathrm{P}$ axis $[37,38,47]$ which are likely to have caused to the first states of plasticity in the vicinity of the WCZ. According to [38], a maximum tensile residual stress peak is located a few millimetres away from the $\mathrm{WCZ}$ on the oscillating workpiece side of the weld. These results are consistent with the fact that localized plastic activity initiates on the oscillating workpiece side, as shown in Fig.10.

Defects and fatigue life scatter. The LFW-1 and LFW-3 fatigue specimens were tested at a maximum stress level of $500 \mathrm{MPa}$. Fatigue life for both specimens were 0.3 and $2 \times 10^{5}$ cycles, respectively. An important fatigue life scatter was found. If the graph of Fig.11 were used as a reference for the design of a workpiece under cycling loading, the fatigue life of the LFW-1 specimen would be very limiting. Hence, it is worthy to better understand the underlying cause of this fatigue life scatter. Both fatigue specimens were pre-polished to a mirror-like state. Thus, it could be stated that the surface roughness of both samples led to similar surface stress concentrations. In Section 3.7.1, a fish-eye crack and the creation of a $\sim 40 \mu \mathrm{m}$ wide internal crack from a dendritic defect on the LFW-1 fatigue specimen during the first fatigue cycles is shown. Consequently, the fatigue crack propagation for the LFW-1 sample occurred with a significant initial stress intensity factor caused by the defect. The threshold of the stage II for the fatigue crack propa-

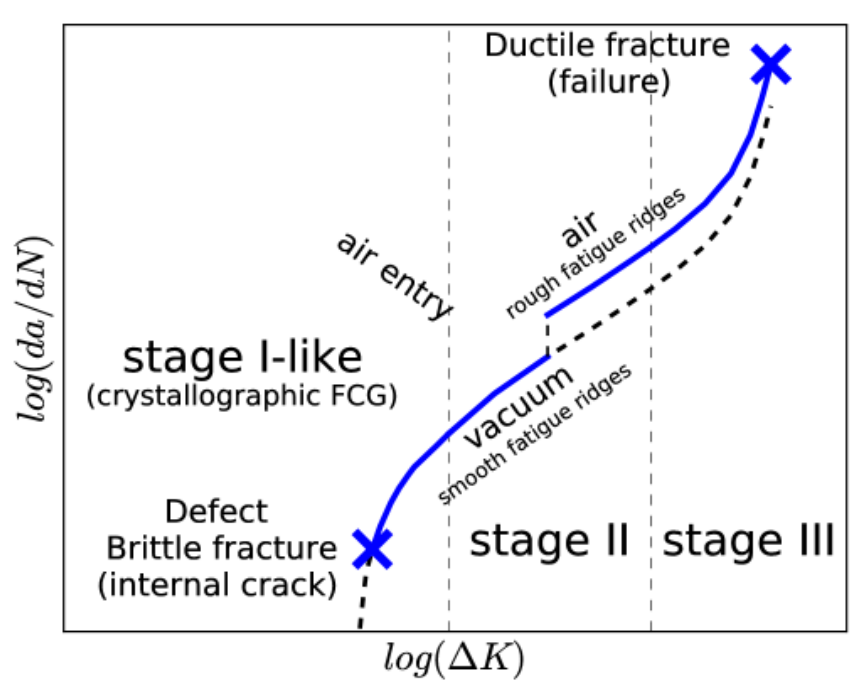

Figure 18: Schematic fatigue crack propagation describing the fatigue scenario of the LFW-1 fatigue specimen. gation is known to take place when the plastic zone size at the crack tip is in the order of several grains. By considering the internal crack as crack in a infinite plate, an approximative and conservative estimation of the stress intensity factor can be made using $\Delta K=\Delta \sigma \times \sqrt{\pi a} \approx 5.16 \mathrm{MPa} \sqrt{\mathrm{m}}$ [58]. Crack size, associated small plastic zone size and the vacuum environment (internal crack) seem to favour a stage I-like propagation [50]. The stress intensity factor continued to increase until reaching stage II. Crack propagation took place at first in vacuum and then in air for the LFW-1 fatigue specimen. [59] have shown that fatigue crack propagation speed is lower for a propagation in vacuum, in particular for stage I-like propagation. Therefore, compared to the LFW-3 fatigue specimen, more cycles should be needed in propagation. Despite the slower fatigue crack propagation, the fatigue life was strongly reduced by the internal crack. The initial stress intensity factor was finally decisive in the trade-off between fatigue crack growth speed and number of cycles for fatigue crack initiation. The fatigue failure scenario for the internal defect is summarized in the schematic graph of Fig.18 and as 
following: during the first cycles of tensile cyclic loading an internal crack was created in the surroundings of brass contaminants hot spots due to a brittle fracture; the stress intensity factor induced by this internal crack favoured a stage I-like fatigue propagation revealing the underlying $\alpha^{\prime}$ acicular martensite microstructure; the growth of the internal fatigue crack continued until the stress intensity factor was enough to favour a stage II fatigue propagation in vacuum; the internal crack reached the specimen surface enabling the air entry and changing the crack propagation environments conditions; oxides layers on the crack tip changed the roughness around the fatigue ridges and increased the fatigue propagation speed; finally, ductile mechanisms are found.

Weld auto-cleaning Certainly, brass contamination should receive special attention. However, It could be argued that EDM cutting is not a commonly used technique in the industry and that industrial cutting techniques could probably less contaminate the surface of the blocks prior to welding. In such case, joints of better quality in terms of defects and fatigue life scatter may have been produced. Furthermore, the choice of welding parameters could be questioned. Increasing power input could favour the extrusion of impurities but conversely increase temperature, promoting further melting in the weld interface. It is worthy to highlight that only the fatigue specimen coming from the centre of the welded joint was affected by this contamination and that the fatigue life scatter would be significantly lower, if this single internal crack initiation had not occurred.

\section{Conclusions}

Similar Ti6242 LFW joints in the as welded state were investigated and compared to the PM. The following conclusions can be drawn:

- The PM microstructure, consisting in equiaxed $\alpha$ grains situated in a $\beta$ matrix, was recrystallized into an entangled acicular $\alpha^{\prime}$ martensite in the $\mathrm{WCZ}$.

- Two populations of nanometric and micrometric voids were observed in the WCZ.

- Microhardness of the PM and the $\mathrm{WCZ}$ were $330 \mathrm{HV}_{0.5}$ and $420 \mathrm{HV}_{0.5}$, respectively. Microhardness showed an increase of $27 \%$. The zone exhibiting modified microhardness was less than $5 \mathrm{~mm}$ wide.

- The weld showed an overmatch. LFW cross-weld samples have shown a strength of $960 \mathrm{MPa}$ such as the PM and a total strain of $9.2 \%$ measured over a $25 \mathrm{~mm}$ basis compared to $14.0 \%$ for the PM.

- Under monotonic loading, failure occurred at the oscillating workpiece, $10 \mathrm{~mm}$ away from the WCZ in the PM.

- An original DIC measurement of the normalized strain rate fields showed an early strain activity close to the WCZ, despite the weld overmatch.

- The fatigue strength for $10^{5}$ cycles of the PM and the LFW cross-weld sample was $\sim 625 \mathrm{MPa}$ and $\sim 600 \mathrm{MPa}$, respectively. LFW fatigue strength was compromised by significant scatter. The fatigue crack initiation site for all samples was located in the vicinity of the TMAZ at a distance of $1.5 \mathrm{~mm}$ away from the WCZ consistent with the early strain activity measured by DIC and probably linked to residual stresses.

- An unexpected internal dendritic defect in the centre of the WCZ caused the reduced fatigue life for a welded joint and led to a fish-eye crack.

- A contamination of $\mathrm{Cu}$ and $\mathrm{Zn}$ was observed in the $\mathrm{WCZ}$ in the dendritic defect. It was attributed to EDM cutting of the blocks before welding and associated local melting/solidification of the brass contaminants during welding. 


\section{Acknowledgements}

The authors wish to thank UTC, CEMEF, Mines-ParisTech and Airbus Central R\&T for the valuable discussions. ACB is thanked for providing the welds for this study. Lukas Helfen at ESRF ID 19 line is gratefully acknowledged for his kind help in non destructive laminographic observations. Henry Proudhon at Centre des Matériaux is thanked for the provided training on the PyMicro library (http://github.com/heprom/pymicro) for the 3D image processing. Vladimir Esin at Centre des Matériaux insight in microstructure analysis is acknowledged. Anne-Françoise Gourgues-Lorenzon at Centre des Matériaux is kindly thanked for the discussions about rupture mechanisms. Steve Dodds at TWI is to be thanked for the discussions about the Strain Induced Porosity phenomenon. The authors acknowledge the financial support from the French National Research Agency (ANR) and FRAE through OPTIMUM ANR-14-CE27-0017 project.

\section{References}

[1] RR Boyer. Attributes, characteristics, and applications of titanium and its alloys. fom, 62(5):21-24, 2010.

[2] TITANIUM USA 2016 Executive Summary. World titanium industry supply and demand overview, 2016.

[3] Global Market Forecast Airbus. Growing horizons 2017-2036, 2017.

[4] RR Boyer. Titanium for aerospace: rationale and applications. Advanced Performance Materials, 2(4):349-368, 1995.

[5] Charlie C Chen. Process for preparation of near-alpha titanium alloys, January 5 1982. US Patent 4,309,226.

[6] W Richter. Herbeifuehrung einer haftverbindung zwischen plaettchen aus werkzeugstahl und deren traegern nach art einer schweissung oder loetung. Patent no. DE477084, 1929.

[7] Achilles Vairis. High frequency linear friction welding. PhD thesis, University of Bristol, 1997.

[8] Bertrand Flipo, Kathryn Beamish, Bryan Humphreys, and Martin Wood. Linear friction welding of $\mathrm{ti}-6 \mathrm{al}-4 \mathrm{v}$ for aerostructure applications. Trends Weld. Res. Proc. 10th Int. Conf., Tokyo, Japan., 2016.

[9] Antonio M Mateo García. Blisk fabrication by linear friction welding. In Advances in gas turbine technology, page 2. InTech, 2011.

[10] A Mateo, M Corzo, M Anglada, J Mendez, P Villechaise, J-P Ferte, and O Roder. Welding repair by linear friction in titanium alloys. Materials science and technology, 25(7):905-913, 2009.

[11] Hiroshi Kuroki, Koji Nezaki, Tsukasa Wakabayashi, and Kenji Nakamura. Application of linear friction welding technique to aircraft engine parts. IHI Eng Rev, 47:40-43, 2014.

[12] Wenya Li, Hui Wu, Tiejun Ma, Changlin Yang, and Zhongwei Chen. Influence of parent metal microstructure and post-weld heat treatment on microstructure and mechanical properties of linear friction welded ti-6al-4v joint. Advanced Engineering Materials, 14(5):312-318, 2012.

[13] W-Y Li, Tie-jun Ma, Yong Zhang, Quan-zhou Xu, Jing-long Li, Si-qian Yang, and Han-lin Liao. Microstructure characterization and mechanical properties of linear friction welded ti-6al-4v alloy. Advanced Engineering Materials, 10(1-2):89-92, 2008.

[14] Loic Debeugny and Guillaume Racineux. Contribution a la modelisation et a la comprehension du procede de soudage par friction lineaire. Ecole Central de Nantes, 2013.

[15] E.C. Dalgaard. Evolution of Microstructure, Microtexture and Mechanical Properties in Linear Friction Welded Titanium Alloys. McGill theses. McGill University Library, 2011. 
[16] Elvi Dalgaard, Priti Wanjara, Javad Gholipour, and John J Jonas. Linear friction welding of a forged near- $\alpha$ titanium alloy. In Materials Science Forum, volume 706, pages 211-216. Trans Tech Publ, 2012.

[17] GD Wen, TJ Ma, WY Li, JL Li, HZ Guo, and DL Chen. Cyclic deformation behavior of linear friction welded ti6al4v joints. Materials Science and Engineering: A, 597:408-414, 2014.

[18] Suresh D Meshram and T Mohandas. A comparative evaluation of friction and electron beam welds of near- $\alpha$ titanium alloy. Materials \& Design, 31(4):2245-2252, 2010.

[19] Pengkang Zhao and Li Fu. Strain hardening behavior of linear friction welded joints between tc11 and tc17 dissimilar titanium alloys. Materials Science and Engineering: A, 621:149-156, 2015.

[20] E Dalgaard, P Wanjara, J Gholipour, and JJ Jonas. Evolution of microstructure, microtexture and mechanical properties of linear friction welded imi 834. Canadian Metallurgical Quarterly, 51(3):269-276, 2012.

[21] A Chamanfar, T Pasang, A Ventura, and WZ Misiolek. Mechanical properties and microstructure of laser welded ti-6al-2sn-4zr-2mo (ti6242) titanium alloy. Materials Science and Engineering: A, 663:213-224, 2016.

[22] JC Stinville, F Bridier, D Ponsen, P Wanjara, and Philippe Bocher. High and low cycle fatigue behavior of linear friction welded ti-6al-4v. International fournal of Fatigue, 70:278-288, 2015.

[23] M De Strycker, P Lava, Wim Van Paepegem, L Schueremans, and D Debruyne. Measuring welding deformations with the digital image correlation technique. Welding fournal, 90(6):107S-112S, 2011.

[24] Caizhi Zhou, Xinqi Yang, and Guohong Luan. Effect of root flaws on the fatigue property of friction stir welds in 2024-t3 aluminum alloys. Materials Science and Engineering: A, 418(1-2):155-160, 2006.

[25] Thomas Le Jolu, Thilo F Morgeneyer, Anne Denquin, and Anne-Françoise Gourgues-Lorenzon. Fatigue lifetime and tearing resistance of aa2198 al-cu-li alloy friction stir welds: effect of defects. International journal of fatigue, 70:463-472, 2015.

[26] P Wanjara and M Jahazi. Linear friction welding of ti-6al-4v: processing, microstructure, and mechanicalproperty inter-relationships. Metallurgical and Materials Transactions A, 36(8):2149-2164, 2005.

[27] Wenya Li, Juandi Suo, Tiejun Ma, Yan Feng, and KeeHyun Kim. Abnormal microstructure in the weld zone of linear friction welded ti-6.5 al-3.5 mo-1.5 zr-0.3 si titanium alloy joint and its influence on joint properties. Materials Science and Engineering: A, 599:38-45, 2014.

[28] B Lang, TC Zhang, XH Li, and DL Guo. Microstructural evolution of a tc11 titanium alloy during linear friction welding. Fournal of materials science, 45(22):6218-6224, 2010.

[29] Thomas Le Jolu, Thilo F Morgeneyer, Anne Denquin, Mohamed Sennour, Anne Laurent, Jacques Besson, and Anne-Françoise Gourgues-Lorenzon. Microstructural characterization of internal welding defects and their effect on the tensile behavior of fsw joints of aa2198 al-cu-li alloy. Metallurgical and Materials Transactions A, 45(12):5531-5544, 2014.

[30] K Elangovan, V Balasubramanian, and S Babu. Developing an empirical relationship to predict tensile strength of friction stir welded aa2219 aluminum alloy. Fournal of materials engineering and performance, 17(6):820, 2008.

[31] Kazuhiro Nakata, Young Gon Kim, Masao Ushio, Takenori Hashimoto, and Shigetoshi Jyogan. Weldability of high strength aluminum alloys by friction stir welding. ISIf international, 40(Suppl):S15-S19, 2000.

[32] S Lomolino, R Tovo, and J Dos Santos. On the fatigue behaviour and design curves of friction stir buttwelded al alloys. International fournal of Fatigue, 27(3):305-316, 2005. 
[33] H Lombard, DG Hattingh, A Steuwer, and MN James. Optimising fsw process parameters to minimise defects and maximise fatigue life in 5083-h321 aluminium alloy. Engineering Fracture Mechanics, 75(3-4):341-354, 2008.

[34] Shusheng Di, Xinqi Yang, Dapeng Fang, and Guohong Luan. The influence of zigzag-curve defect on the fatigue properties of friction stir welds in 7075-t6 al alloy. Materials chemistry and physics, 104(2-3):244-248, 2007.

[35] L Ceschini, I Boromei, G Minak, A Morri, and F Tarterini. Effect of friction stir welding on microstructure, tensile and fatigue properties of the aa7005/10 vol.\% al2o3p composite. Composites science and technology, 67(3-4):605-615, 2007.

[36] MN James, DG Hattingh, and GR Bradley. Weld tool travel speed effects on fatigue life of friction stir welds in 5083 aluminium. International fournal of Fatigue, 25(12):1389-1398, 2003.

[37] P Frankel, M Preuss, A Steuwer, PJ Withers, and S Bray. Comparison of residual stresses in ti-6al-4v and ti-6al-2sn-4zr-2mo linear friction welds. Materials Science and Technology, 25(5):640-650, 2009.

[38] J Romero, MM Attallah, M Preuss, M Karadge, and SE Bray. Effect of the forging pressure on the microstructure and residual stress development in ti-6al-4v linear friction welds. Acta Materialia, 57(18):5582-5592, 2009.

[39] GA Webster and AN Ezeilo. Residual stress distributions and their influence on fatigue lifetimes. International fournal of Fatigue, 23:375-383, 2001.

[40] D Ballat-Durand, S Bouvier, M Risbet, and W Pantleon. Through analysis of the microstructure changes during linear friction welding of the near- $\alpha$ titanium alloy ti-6al-2sn-4zr-2mo (ti6242) towards microstructure optimization. Under preparation, 2018.

[41] Anthony R McAndrew, Paul A Colegrove, Adrian C Addison, Bertrand CD Flipo, and Michael J Russell. Energy and force analysis of ti-6al-4v linear friction welds for computational modeling input and validation data. Metallurgical and Materials Transactions A, 45(13):6118-6128, 2014.

[42] Yang Shen, Thilo F Morgeneyer, Jérôme Garnier, Lucien Allais, Lukas Helfen, and Jérôme Crépin. Threedimensional quantitative in situ study of crack initiation and propagation in aa6061 aluminum alloy sheets via synchrotron laminography and finite-element simulations. Acta Materialia, 61(7):2571-2582, 2013.

[43] Lukas Helfen, Feng Xu, Heikki Suhonen, Peter Cloetens, and Tilo Baumbach. Laminographic imaging using synchrotron radiation - challenges and opportunities. Journal of Physics: Conference Series, 425(19):192025, mar 2013.

[44] Gilles Besnard, Sandra Guérard, Stéphane Roux, and François Hild. A space-time approach in digital image correlation: Movie-dic. Optics and Lasers in Engineering, 49(1):71-81, 2011.

[45] Sicong Ren, Matthieu Mazière, Samuel Forest, Thilo F Morgeneyer, and Gilles Rousselier. A constitutive model accounting for strain ageing effects on work-hardening. application to a c-mn steel. Comptes Rendus Mécanique, 345(12):908-921, 2017.

[46] František Chmelík, Frank B. Klose, Hanno Dierke, Jindřich Šachl, Hartmut Neuhäuser, and Pavel Lukáč. Investigating the portevin-le chatelier effect in strain rate and stress rate controlled tests by the acoustic emission and laser extensometry techniques. Materials Science and Engineering: A, 462(1):53 - 60, 2007. International Symposium on Physics of Materials, 2005.

[47] YC Kim, A Fuji, and TH North. Residual stress and plastic strain in ai51 3041 stainless steel/titanium friction welds. Materials science and technology, 11(4):383-388, 1995. 
[48] Takeshi Naito, Hideo Ueda, and Masao Kikuchi. Fatigue behavior of carburized steel with internal oxides and nonmartensitic microstructure near the surface. Metallurgical Transactions A, 15(7):1431-1436, 1984.

[49] Yu Murakami, T Nomoto, and T Ueda. On the mechanism of fatigue failure in the superlong life regime ( $n>10^{7}$ cycles). part ii: a fractographic investigation. Fatigue \& fracture of engineering materials \& structures, 23(11):903-910, 2000.

[50] Hayat Abdesselam, Jérôme Crépin, André Pineau, A-L Rouffie, P Gaborit, L Menut-Tournadre, and T-F Morgeneyer. On the crystallographic, stage i-like, character of fine granular area formation in internal fish-eye fatigue cracks. International fournal of Fatigue, 106:132-142, 2018.

[51] Ian Polmear and David St John. Light alloys: from traditional alloys to nanocrystals. ButterworthHeinemann, 2005.

[52] Hiroshi Hayakawa, Nobuo Fukada, Takeshi Udagawa, Masaaki Koizumi, Hirowo G Suzuki, and Takashi Fukuyama. Solidification structure and segregation in cast ingots of titanium alloy produced by vacuum arc consumable electrode method. ISIf International, 31(8):775-784, 1991.

[53] Jean Petit and C Sarrazin-Baudoux. Some critical aspects of low rate fatigue crack propagation in metallic materials. International fournal of Fatigue, 32(6):962-970, 2010.

[54] B. Predel. Cu-zn (copper-zinc): Datasheet from landolt-börnstein - group iv physical chemistry - volume 5d: "cr-cs - cu-zr" in springermaterials (https://dx.doi.org/10.1007/10086090_1134).

[55] Anthony R McAndrew, Paul A Colegrove, Adrian C Addison, Bertrand CD Flipo, and Michael J Russell. Modelling the influence of the process inputs on the removal of surface contaminants from ti-6al-4v linear friction welds. Materials \& Design (1980-2015), 66:183-195, 2015.

[56] SL Semiatin, V Seetharaman, and I Weiss. The thermomechanical processing of alpha/beta titanium alloys. fom, 49(6):33-39, 1997.

[57] S Tamirisakandala, Steve C Medeiros, William G Frazier, and YVRK Prasad. Strain-induced porosity during cogging of extra-low interstitial grade ti-6al-4v. Fournal of Materials Engineering and Performance, 10(2):125-130, 2001.

[58] Yukitaka Murakami. Metal fatigue: effects of small defects and nonmetallic inclusions. Elsevier, 2002.

[59] Christine Sarrazin-Baudoux, Sandrine Lesterlin, and Jean Petit. Atmospheric influence on fatigue crack propagation in titanium alloys at elevated temperature. In Elevated temperature effects on fatigue and fracture. ASTM International, 1997. 